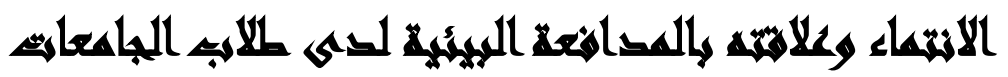

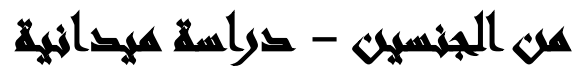

\section{[ᄉ]}

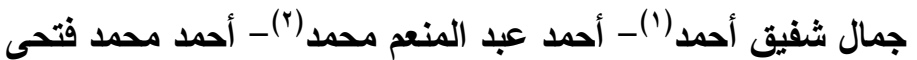

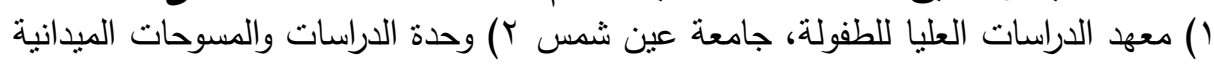

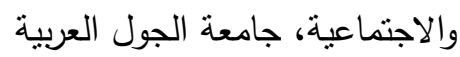

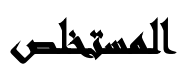

تتنمى هذة الدراسة إلى نمط الدراسات الوصفية التحليلية والتى تهدف إلى وصف وتحليل

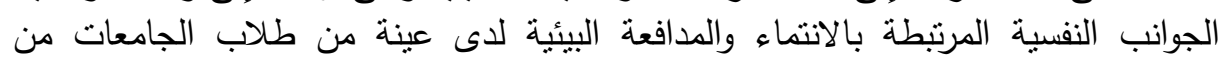

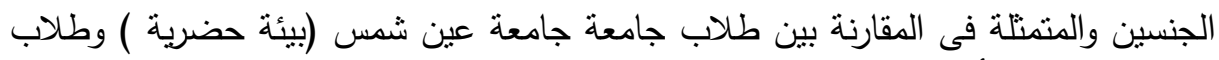

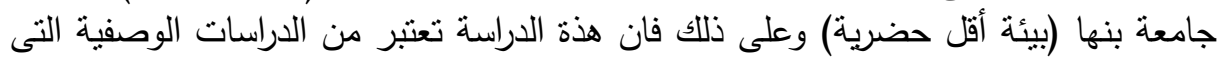

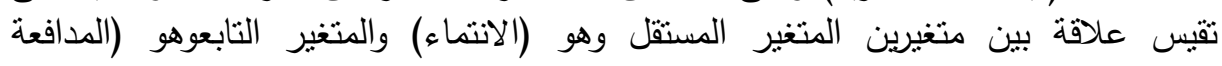

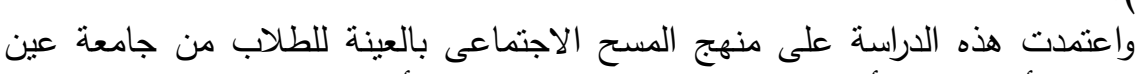

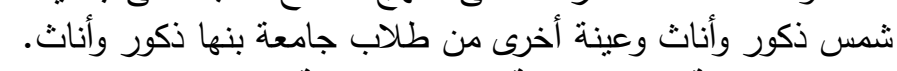
وتحاول الاراسة اختبار صحة الفروض التان التالية:

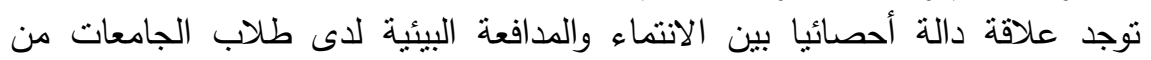

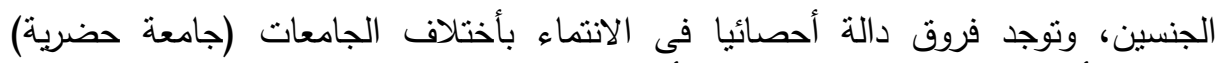

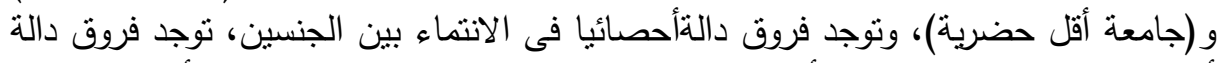

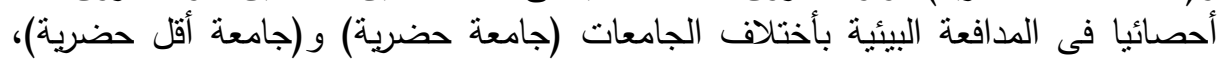
وتوجد فروق دالة إحصائيا فى الدافعة البيئية بين الجنائين الجنين.

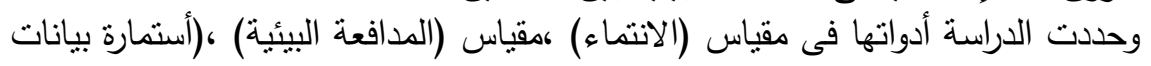

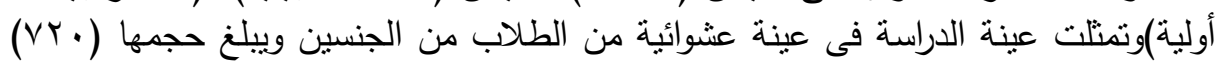

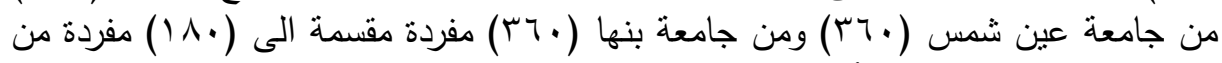

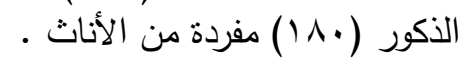
كما تم معاجة البيانات باستخدام: اختبار ت للكثف عن الفراث الفروق الفردية بين المتوسطات

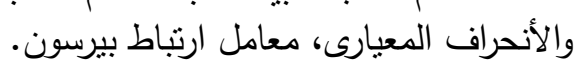
وقد توصلت الداسلة الى: وجود علاقة ارتباطباطية طردية بين الانتماء والددافعة البيئية لدى

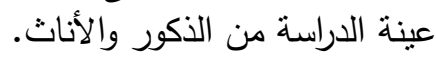


توصيات الدراسة: دعوة المجتمع المدنى ومؤسسات الدولة للقيام بدورهم من خلال عمل بلدي

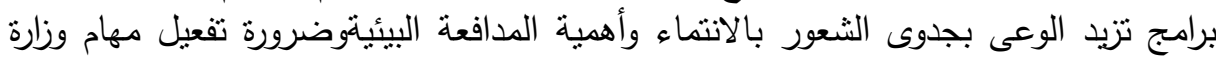

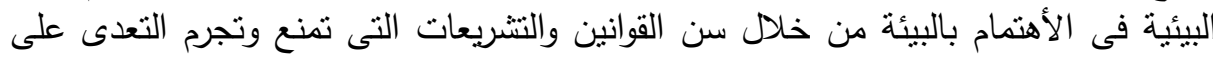

\section{rasadl}

يعد مفهوم الانتماء من المفاهيم العالمية المهمة في عالمنا المعاصر الذي أصبح من

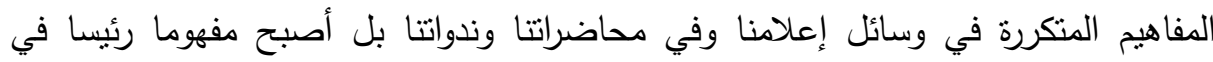

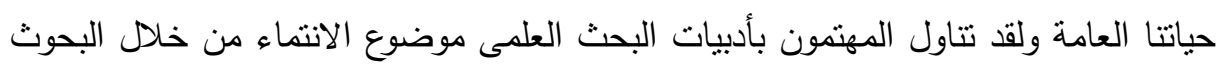
التربوية والكتب المتخصصة من خلال إيراد تعريفات لمفهوم الانتماء ومدلولاته ولقد أرتبط

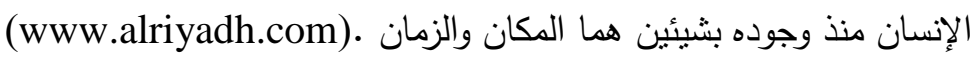

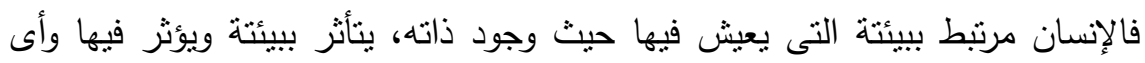

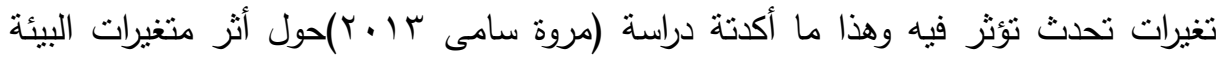

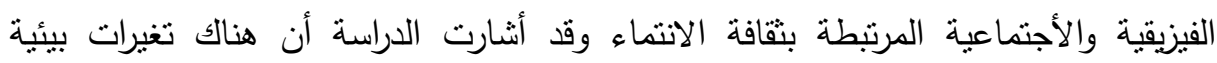

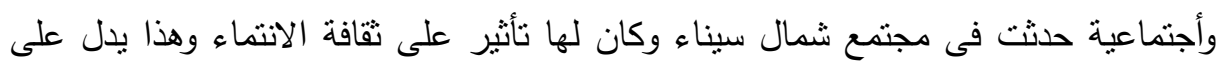

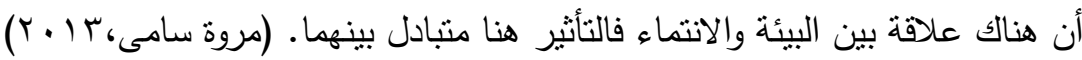
ونظرا لظهور العديد من المشكلات البيئية كشكلات تلوث الهواء والماء والتربة وتغير التهاء

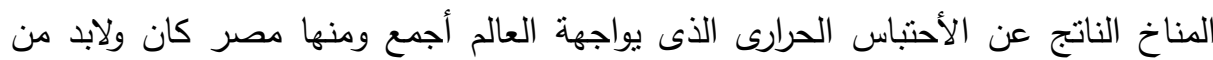

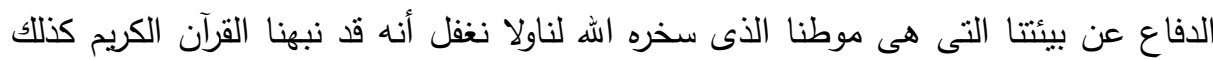

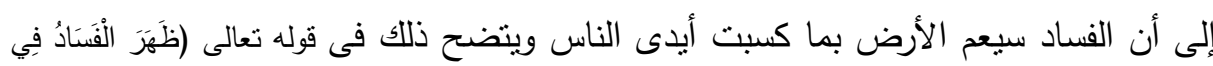

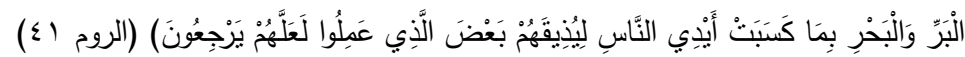

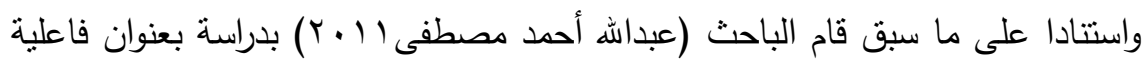

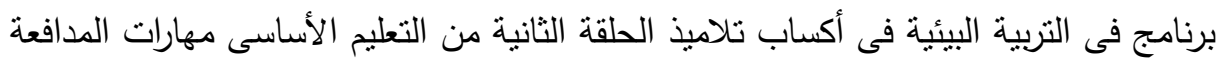

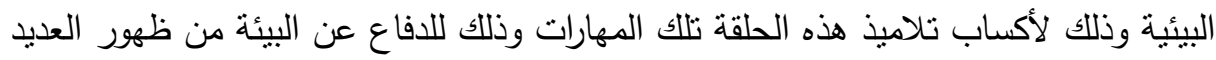


من المشكلات البيئية والتى نتجت بسبب عدم وعى الأنسان وسلوكياتة الخاطئة مع البيئة.

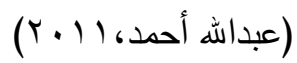

فيرى أستاذ الفلسفة والكونيات (جون ليزلى) فى كتابة نهاية العالم أن الجنس البشرى

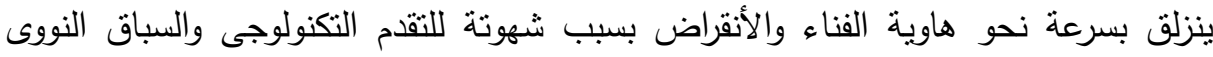
والتجارب الفيزيائية شديدة الطموح التى تكاد تتسف الغلاف الجوى ومن حولة ويقوم الكتاب لهن على نظرية العالم (براندون كارتر) عن جدلية يوم القيامة والتى تستتد حجتها الى أن الأنسان

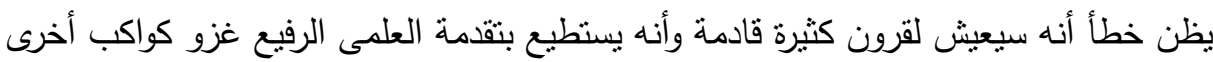
أذا ضاقت به الأرض ولكن هذا الحلم لن بحدث فهناك أسباب كثيرة ومخاطر تهدد بفناء الجنس البشرى فى نهاية القرن الحادى والعشرين بعد مائة عام من الأن حيث بنهاية القرن

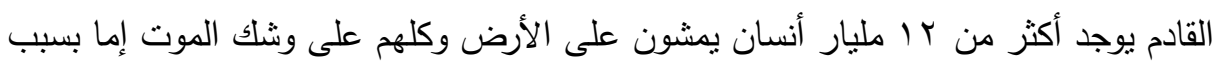

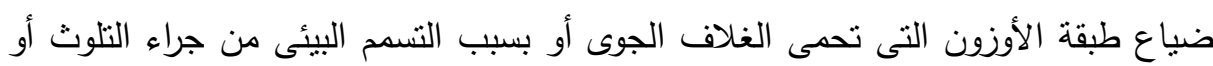
من أثثار حرب نووية أو انتشار فيروس قاتل فتكون حرب جرثومية تفنثل أمامها تحصينات الدول فى اكتشافها بالأضافة إلى ظاهرة الأحتباس الحرارى وتنغير مناخ الكرة الأرضية. (www.startimer.com) لذلك كان ولابد من الدفاع عن البيئة الطبيعية وتتمية الأحساس بالانتماء للمجتمع فقد

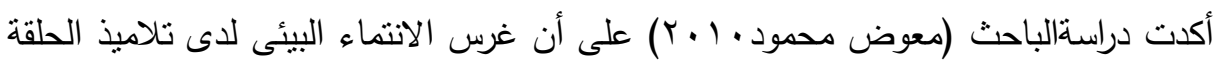

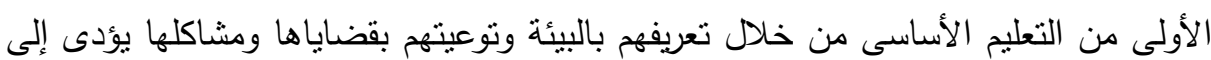

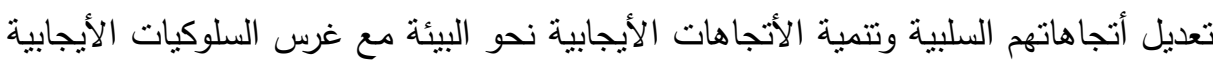

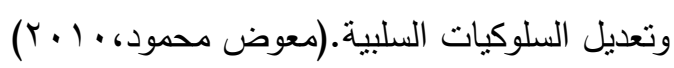
وذللك للتأكيد على أنه بأمكان الجيل الحالى أن يقف ويتصدى لتللك الأخطار التى تواجهة البيئة لنحافظ على هذا الكوكب الذى نحن فى مصرنا الحبيبة جزء لا يتجزاء منه لوقف لوف لهن

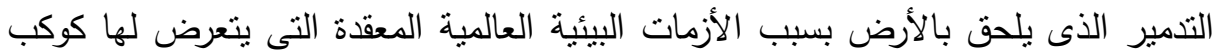




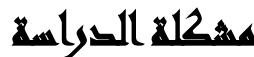

نجد أنه فى الفترة الأخيرة أزدادت التحديات العلمية والثقنية والأقتصادية والسياسية نتيجة لما تمر به البلاد من ظروف عصيبة تؤدى إلى ضعف الانتماء وتفكك روابطةوهذا ما أكدتة

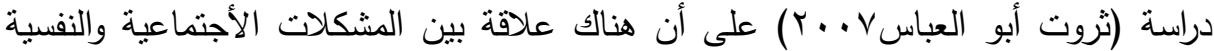
والانتماءونجد أن معظم علماء النفس أكدوا على أهمية الحاجة للأنتماء لكل من الفرد والمجتمع لما لله من دور هام وفعال فى تحديد علاقات الأفراد ببعضهم البعض والمجتمع ماءه والوطن بل وتوجية سلوكياتهم نحو أنفسه وبيئتهم التى يعيشون فيها وكيف يمكن للأنتماء أن

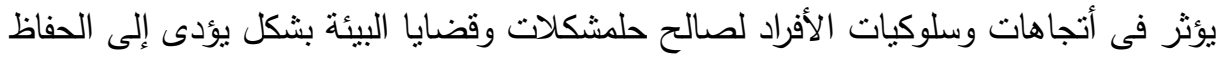
والدفاع عن البيئة المصرية لنتمكن من اللحاق بالدول المتقدمة وسد الفجوة التى تفصلنا عنها وهذا بتطلب بذل الجهود للحفاظ على بيئتا ومواردنا الطبيعية فنرى كيف يمكن لأنتماء الطلاب أن يؤثر فى أستجابتهم للجهود التى تبذل فى سبيل حل مشاكل وقضايا البيئة ،وتؤكد

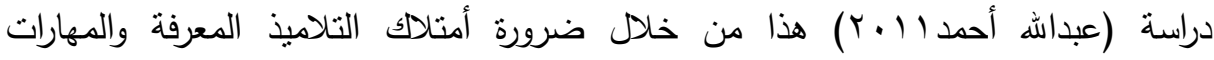
والمواقف التى تمكنه وتتجعهم على تبنى سلوكيات مسؤولة تجاه البيئة. ونجد أن طلاب الجامعات فى مصر هم المحك الرئيسى للوطن فهم بناة المستقبل ورجال

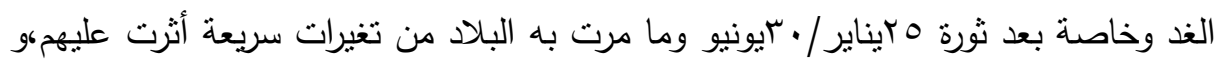

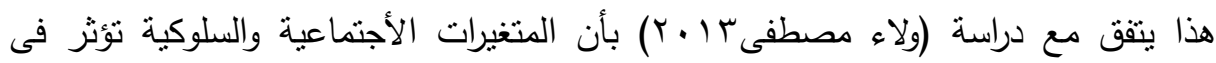
الأستجابة للجهود التى تبذل فى سبيل حل مشاكل وقضايا البيئة لأفراد المجتمع.

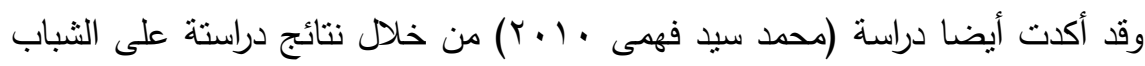
ضعف مشاركة الثباب فى مشروعات الخدمة العامة وضعف الثقافة السياسية للثباب فقدان الثقافة الوطنية مع تشويش المعارف والمعلومات الدينية مع الأهنمام بالأغانى والأفلام

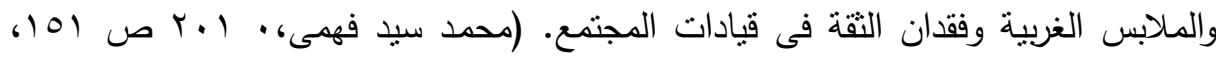


كذلك هناك دراسات أوضحت أهمية الدفاع عن البيئة مع التركيز على التعليم والمواطنة دراسة شيس ستيف ؟ . . r: هدفت الدراسة الى تطوير برنامج فى المدافعة البيئية لتدريب

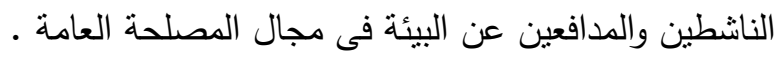
وتوصلت الدراسة الى النتائج التالية: ه التركيز على التعليم والتربية والمواطنة والتدريب النشط للناشطين البيئيين فى المجتمع

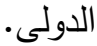

• وضع أستراتيجية لحل القضايا البيئية التى تدخل فى أطار المصلحة العامة بمشاركة

المجتمع المدنى .(Chase, steve, 2006).

بينما أنثار (Bhargavi,2009 ) فى ورقة عمل مقدمة للمنتدى الأسيوى للحوار بين

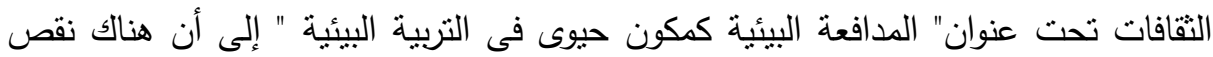
كبير داخل النظم التربوية لنتمية مواطنين مدافعين عن البيئة فى المستقبل،وقد قدم الباحث

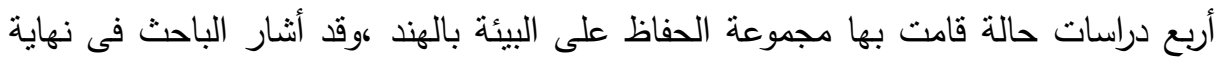
ورقة العمل إلى أن دمج المدافعة البيئية مع التربية البيئية ليس صعبا لأن المدافعة البيئية

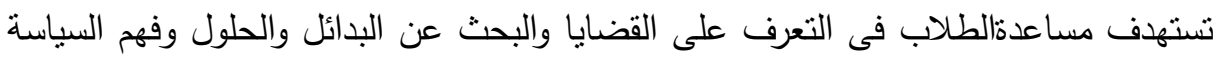
ورفع الوعى المجتمعى لتحسين فهم المجتمع للقضايا البيئية المعقدة. (Bhargavis.(2009). Asian forum for cross- cultural)

أما دراسة (Solmonson,2010) فقد استهدفت تتمية مهارات المدافعة البيئية من خلال برنامج تدريبى تم أعدادة وتطبيقة على (•^)طالب وقد أشتنمل البرنامج على ثلاثة

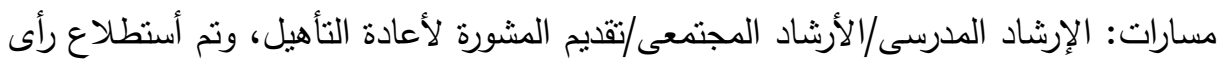

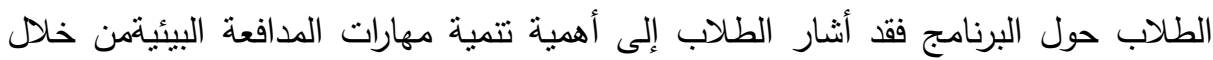
الدورات التدريبية وأن هذة الدورات ساهمت فى نتمية المشاركة والمسؤليةالأجتماعية والثقة

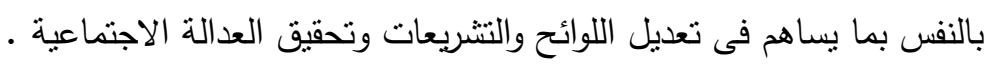
(Solmonson,L.(2010)Developing advocacy skills) 
وأخيرا أشنارت دراسة(Blair,2012)إلى أهمية دمج مهارات المدافعة البيئية مع التربية

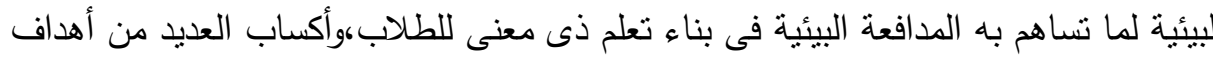

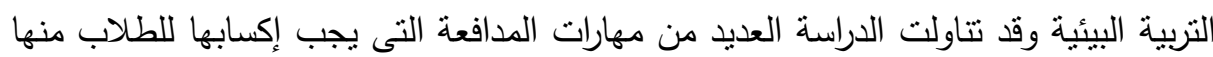

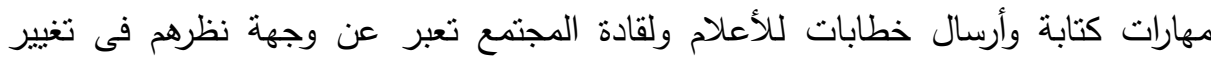
المناخ كإحدى المشكلات البيئية العالمية ولية (Blair,N.(2012).inteegrating Advocacy and Environmental Education) . من خلال ما سبق عرضه وتحليلة من ما سبق ونتائجة المرتبطة بالانتماء والمدافعة البيئية، والأستفادة من نتائج الدراسات السابقة. ولوجود فجوه بحثية في تحديد العلاقة بين الانتماء والمدافعة البيئيةونتيجة لنلك الفجوة وقصور الدراسات والبحوث وعدم وجود خطط حماية ومدافعة متكاملة وبرامج المدافعة البيئية ضعيفة وتعد دليل رفاهية وليس برامج علاجية واقية. وأنطلاقاً من أهية الحد من المشكلات البيئية وتدهور الوعى البيئي لدى أفراد المجتمع بلديه ونظراً لندرة الدراسات والبحوث الميدانية التي تتاولت موضوع العلاقة بين الانتماء والمدافعة البيئية بصفة عامة وعلى ومفهوم المدافعه البيئية بصفة خاصة، فإن هذه الدراسة تحاول الكثف عن طبيعة هذه العلاقة بين الانتماء والمدافعة البيئية.

\section{أسهولم المهيم}

1-ما مدى وجود علاقة بين الانتماء والمدافعة البيئة لدى طلاب الجامعات من الجنسين .

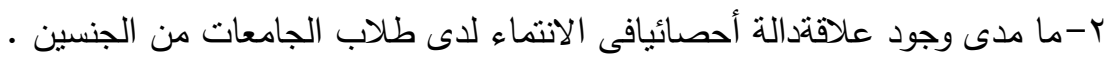
r-ما مدى وجود علاقة دالة أحصائيا فى المدافعة البيئة لاى طلاب الائس الجامعات من الجنسين. 


\section{أهساهيخ الصراسمة}

تهاف الاراسة إلى الإجابة عن تساؤلاتها المتعلقة بـ :

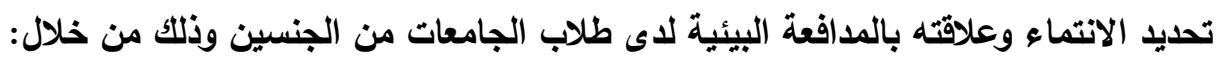
• تحديد الفروق في معنى الانتماء لـؤلاء الطلاب من الجنسين.

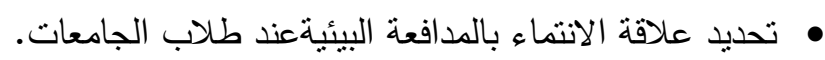

• • تحديد أنماط العلاقه بين الاتنماء والمدافعة البيئية. • تحديد الفروق بين الطلاب الذكور والإناث في مدى وعيهم بالانتماء وعلاقته بالمدافعة البيئية. • تحديد الفروق في السلوكيات البيئية والممارسات التى يمارسها كلا الجنسين. • تحديد الفروق فيممارسة المدافعة البيئية بين الطلاب من الجنسين.

\section{هغونه الكراسلة}

1-نوجد علاقة دالة أحصائيا بين الانتماء والمدافعة البيئية لدى طلاب الجامعات من

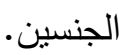
r-توجد فروق دالة أحصائيا فى الانتماء بأختلاف الجامعات (جامعة حضرية) و (جامعة أقل حضرية). ب-توجد فروق دالة أحصائيا فى الانتماء بين الجنسين.

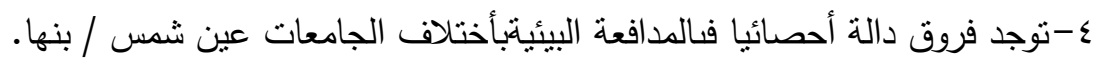
ه-توجد فروق دالة أحصائيا فى المدافعة البيئية بين الجنسين. 


\section{أهمية الصوراسما}

\section{وتنقسم أهمية الاراسة الحالية إلى:}

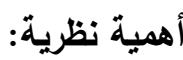

1-إن الدراسات النى تتاولت قضية الاتنماء رغم أهميتها لم تغط سوى جوانب قليلة ومازال الموضوع فى حاجة إلى مزيد من البحث والدراسة فالانتماء يعد من القضايا ذات الأبعاد

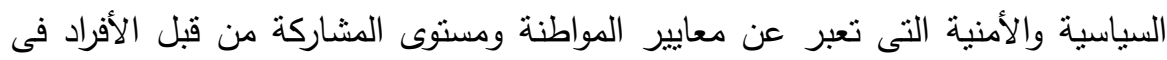
حماية مجتمعهم وبيئتهر.

r-قلة الدراسات التى نتاولت قضية المدافعة البيئة من المنظور النفسي على الرغم من أرتباط المدافعة البيئية بالعديد من المفاهيم النفسية ( مفهوم القيم مفهوم الصحة النفسية مفهوم

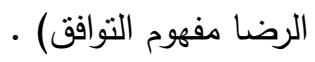

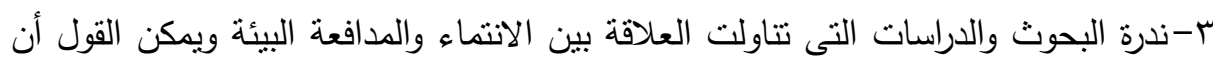
هذة الدراسة تعتبر المحاولة الأولى لطرق هذة القضية الحيوية فى مجال علم النفس البيئى

ع- إنها تتعامل مع طلاب الجامعات حيث أنهم الركيزة الأساسية لأى مجتمع ويمثلوا قوة لا يستهان بها فى المجتمع فهم كفئة عمرية نصف الحاضر وكل المستقبل.

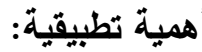

1-أمكانية الأستفادة من نتائج هذا البحث لتقديم تصور علمى عن الانتماء لاى طلاب

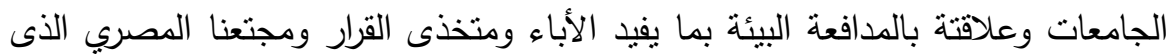
فى حاجة شديدة إلى ذلك خصوصا فى هذا الوقت الراهن الذى تمر به البلاد .

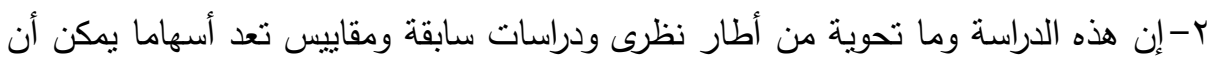

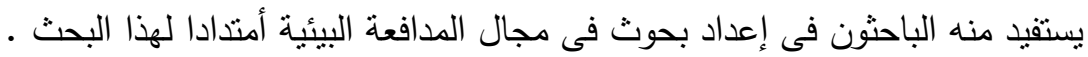
r-المساهمة فى وضع برامج تتمى الانتماء والثتعور بواجب المدافعة عن البيئة. 


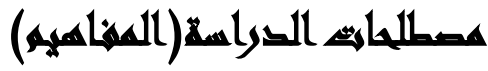

(Affilation) (الانتماء)

الانتماء لغويا: أصل الانتماء فى اللغة العربية هى نم الثئ ويقال إلى أبيه أو نسبته إلبه، ويقال أنماه إلى حجة أى رفع نسبة إليه، أى أنتمى فلان إلى فلان إذاء إنى أرتقع إليه فى النسب،

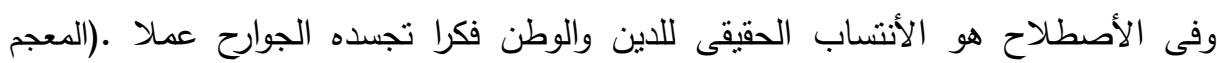

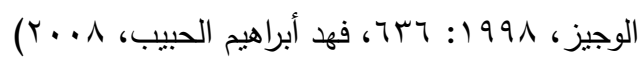

وفى قاموس لسان العرب ينتمى إى يرفع إليه وفى الحديث من إدعى إلى غير أبيه، أو أو إه

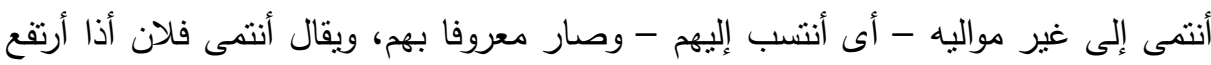

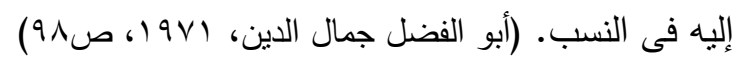

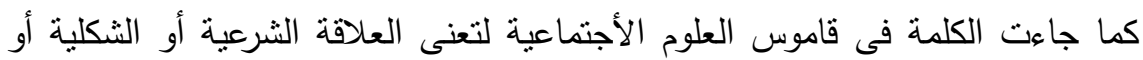
التعاونية بين جماعتين أو أكثر أو الأنضمام إلى جمعية أو رابطة لمجرد التأييد والمساندة

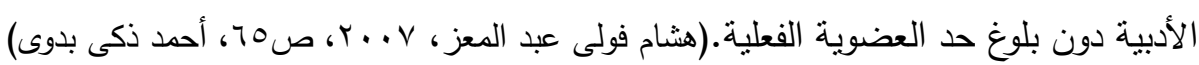

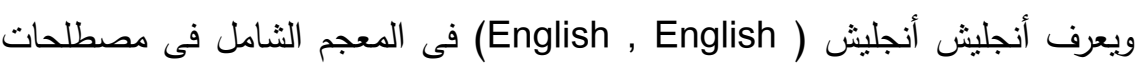
علم النفس والتحليل النفسى أن الانتماء بانه هو: أتجاه يستشعر من خلاله الفرد بتوحده

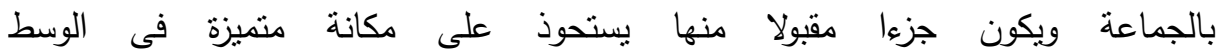
الاجتماعى. (English , English , 1985, P. 64)

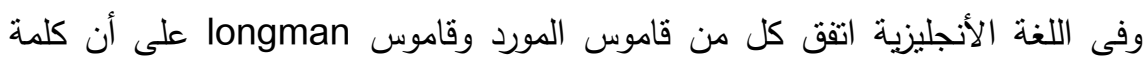
(Belongingness) (longman Dictionary, 1987, P. 83) ويعرف قاموس علم الأجتماع الأانتماء بأنه: شعور التوحد الكامل مع جماعة معينة وأن

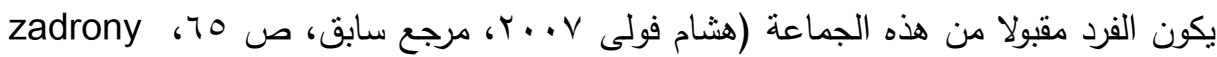
(Dicationar 
برى قدرى حفنى أن الانتماء يعنى فى أبسط صورة شعور الفرد بأنه جزء من مجموعة

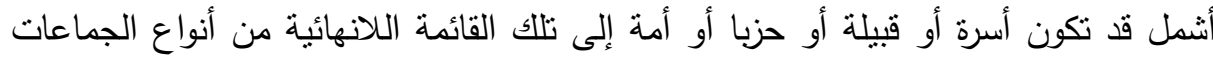

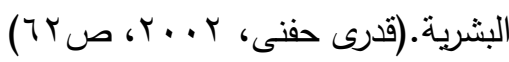

يرى فهد أبراهيم الحبيب أن الانتماء هو شعور داخلى يجعل المواطن يعمل بحماس وأخلاص للأرتقاء بوطنة وللافاع عنه، أو هو أحساس تجاه أمر معين يبعث عن الولاء لهور له

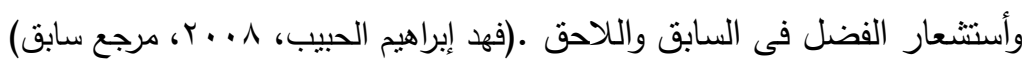

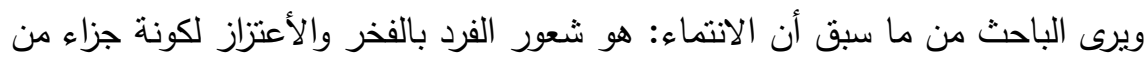

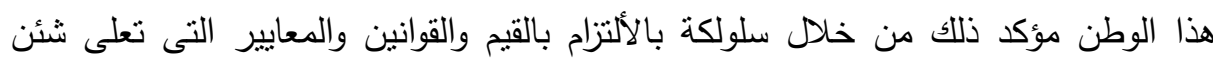
الوطن. تعريف الانتماء إجرائيا: الانتماء هوحاجة الفرد إلى الارتباط بالأخرين والتوحد معهم بما يشعره

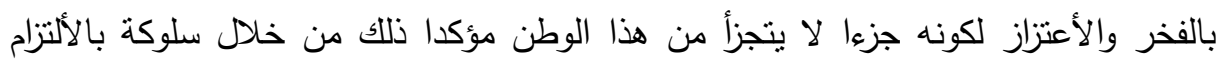
بالقيم والقوانين والمعايير التى تعلى من شأن الوطن وتقديرة لتاريخة ونقافتة دع الأهنمام بأخبار

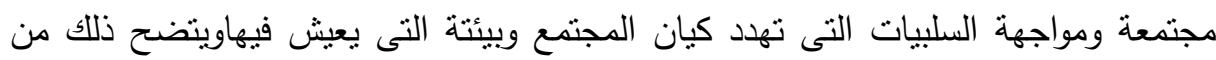
خلال الدرجة النى يحصل عليها الطلاب على أبعاد المقياس (أعداد الباحث) r-المدافعة البيئية (Environmental Advocacy): والمدافعة البيئة كأى مدافعة توصف بأنها عملية وهذا يجعل لها طبيعة دينمايكية ودائمة كما أنها تستخدم أساليب

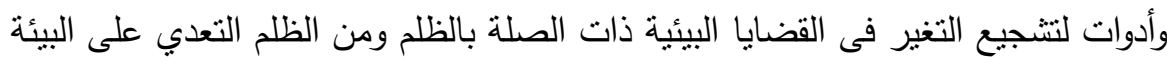
فهذا التعدى هو الذى أحدث خلا فى التوازن البيئى مما نتج عنة أثنار ضارة فى البيئة

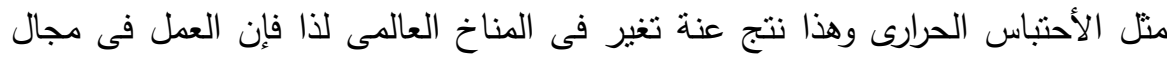
المدافعة البيئة هو تعبير عن التفاعل النشط بين المدافعين وبين أولائك الذين توجة أليهم جهود المدافعة فالمدافعة هى عملية متعددة متعددة للتحدث عن القضايا البيئية الهامة

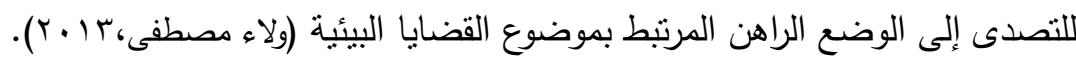


المدافعة لغة: أن يترافع شخص نيابة عن أخر أو عن قضية وتعنى باللاتينية

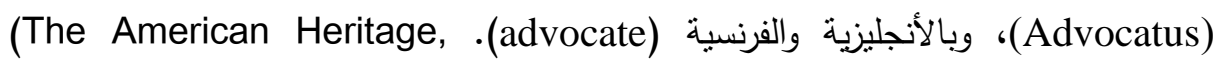

وهو مصطلح له أصول يونانية وتعنى تقديم المدافعة لجعل ما ينبغى أن يكون يحدث

ويكون. (Dictionart.com, 2009)

ولاحظ الباحث أن مصطلح أفوكانو يرد على لسان بعض الناس من العامة، وهؤلاء

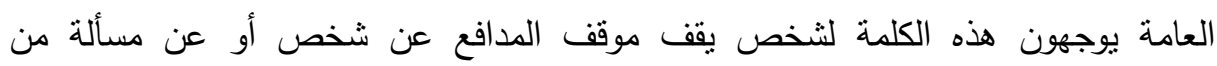

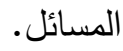

تعريف المدافعة: المدافعة لها صور متعددة، وكل صورة لها أبعادها المختلفة ومن هنا تعددت

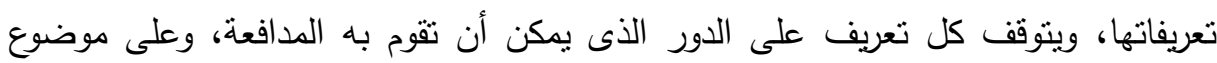

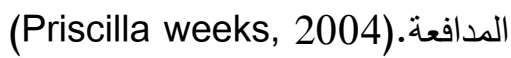
ومن هذه التعريفات: عرفت مجموعة من المعاجم الأجنبية المدافعة بأنها " الفعل أو العمل أو

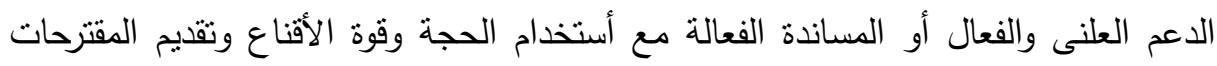
والمشورة وذلك من قبل الأفراد الذين يعتقدون فى فكرة، أو سياسة، أو قضية، لدعم أى منها،

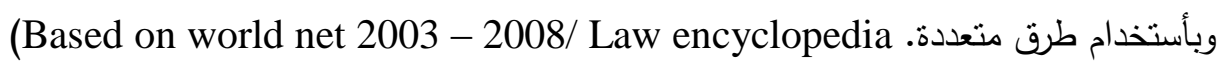
1998/Collins essential / The american heritage / Merriam 1996) كما هناك أدلة من القرآن الكريم على أهمية الددافعة لدفع الضرر الذى يسبب الفساد فى

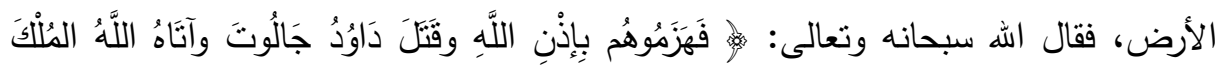

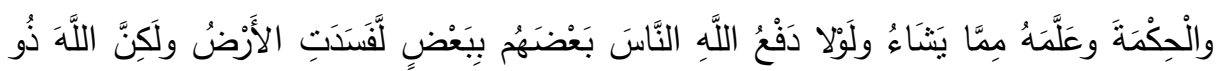

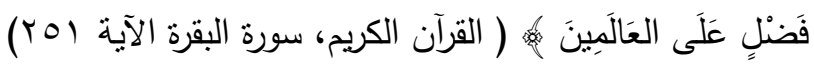


كما عرفها مجموعة من العلماء بالتعريفات الاتية:انها تمثل سلسلة من الإجراءات التى نم اتخاذها نيابة عن القضايا النى سلط الضوؤ عليها وذلك لتغيير ما هو كائن الى ما ينبغى أن يكون باعنباره هو الأفضل.

Cohen, D., R. de la Vega G. Watson, 2001)

التعريف الأجرائى للمدافعة البيئية: العمل والمساندة الفعالة من قبل أفراد المجتمع الذين

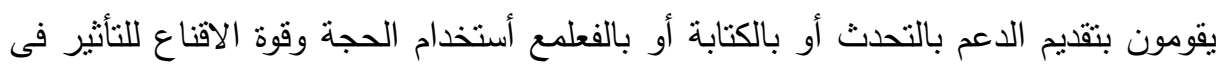
الاخرين وذلك لصالح القضايا والمشكلات البيئية لتغييرما هو قائم الى أفضل وضع دانع مدكن ويتضح ذلك من خلال الدرجة التى يحصل عليها الطلاب على أبعاد المقياس (أعداد

\section{(Universities Studint): بلاب الجامعات}

يقصد بهم الثباب فى هذة الدراسة من حيث الأفراد الذين تقع اعمارهم بين ^1 الىى بـ سنة والثباب في اللغة العربية هو من أدرك سن البلوغ الى سن الرجولة والثباب يعنى الحداثة

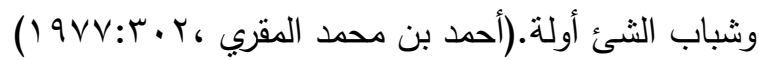
ومن الناحية السيكولوجية نجد أن علم النفس بركز فى تعريف الثباب على أنة مرحلة من مراحل العمر تتميز بالقابلية للنمو فى النواحى النفسية والجسمية والعقلية والأجتماعية لهنية

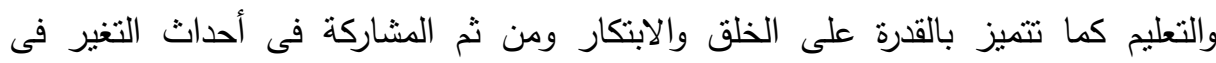

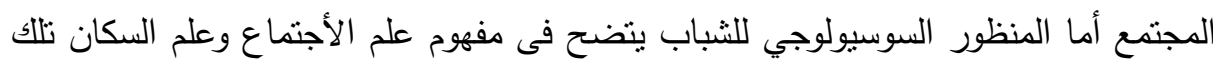

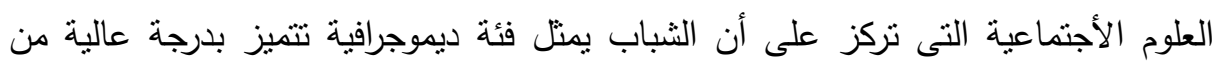

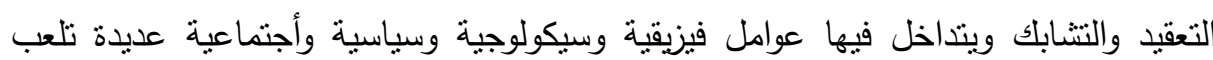
بشكل أو بأخر دور حاسما فى تحديد طبيعتها وأتجاهها من تجمع إلى أخر ومن حضارة

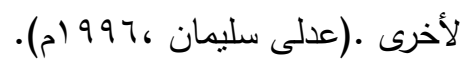




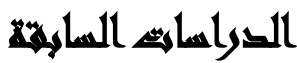

لقد أجريت العديد من الدرسات السابقة عن الانتماء ولكنها لم تتطرق إلى الجانب البيئي الخاص بالمدافعة البيئية بشكل مباشر بل أن أغلب هذة الدراسات كانت تربط الانتماء

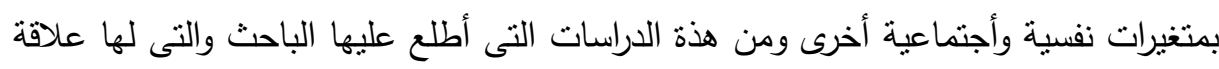
بموضوع الدراسة الراهنة الدراسات الأتية: ا -دراسة تورنى ويارتا(ץ . . ץ): وهدفت الدراسة إلى التعرف على علاقة تدريس محتوى

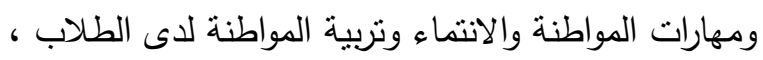

تكونت العينة من ثمان وعشرين دولة شارك فيها تسعون ألف طالب ممن تقع أعمارهم

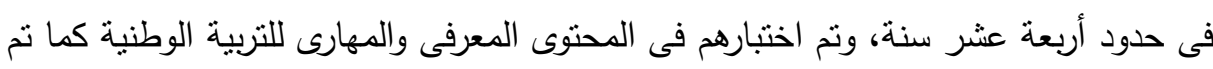
التعرف على آرائهم حول مفاهيم المواطنة ومواقفه تجاه المؤسسات الحكومية والمدينة.

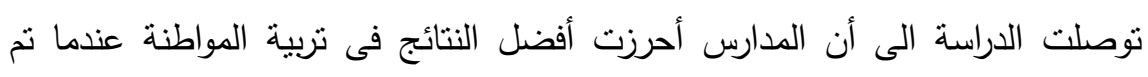
تدريس محتوى ومهارات المواطنة ضمن جو الفصول الدراسية المفتوحة لمناقثة قضايا المواطنة والتركيز على أهمية العمل الوطنى، وتشجيع التكامل بين المدارس ومؤسسات المجتمع.بو) (Torney - Purta - Judith, Lehmann, R, 2002, P. 100)

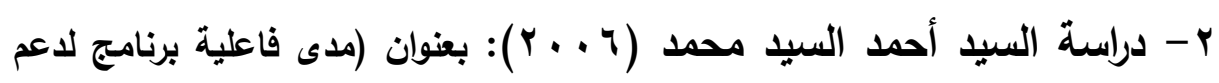
الثعور بالانتماء للوطن لدى تلاميذ الحلقة الثانية من التعليم الأساسى).

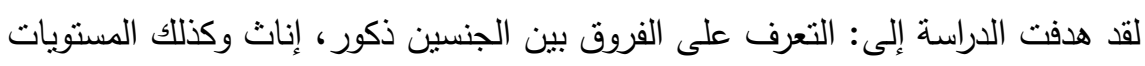

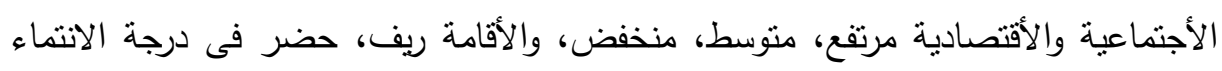

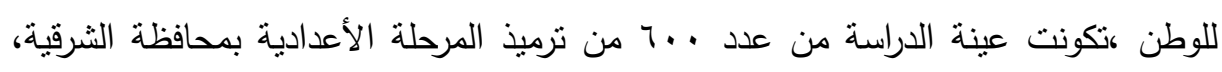

وتتكون عينة الدراسة التجريبية من عدد ؟7 من التلاميذ منخفضى الثعور بالانتماء للوطن. وهدفت الدراسة إلى التعرف على مدى فاعلية البرنامج المقترح فى دعم الثعور بالانتماء للوطن لدى المراهقين، أستخدم الباحث المنهج الوصفى، المنهج التجريبى 


\section{وقد توصلت الاراسة إلى النتائج الآتية:} ا. وجود فروق ذات دلالة أحصائية بين متوسطى درجات الذكور والأناث من الثعور

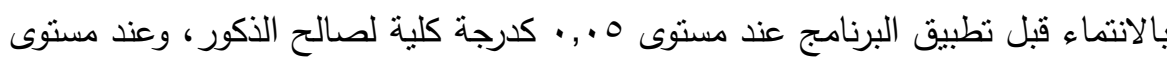

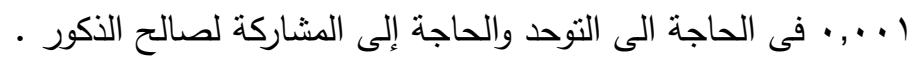

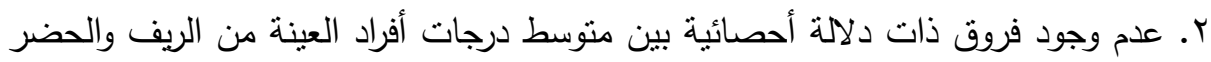

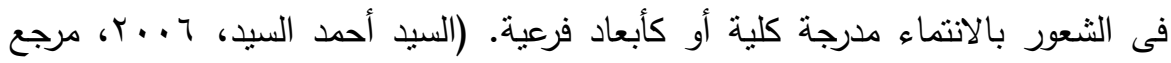

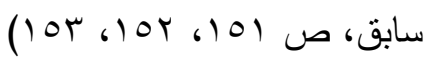

r-دراسة ثروت أبو العباس عثمان أحمد (V . . r): بعنوان ( العلاقة بين بعض المشكلات الأجتماعية والنفسية للشباب والانتماء )

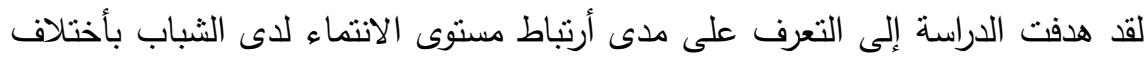
البيئات التى ينتمى أليها وجه بحرى - وجه قبلى، التعرف على درجة وترتيب جماعات

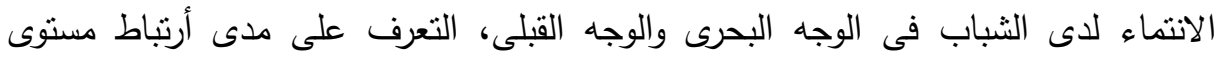
الانتماء بـ: (نوعية عمل وتعليم الوالدين/ أختلاف السن والنوع/ المسنوى الأفتصادى للوالدين) تكونت عينة الدراسة من •10 شاب وفتاة موزعين على الوجه البحرى والوجه القبلى من الثباب طلاب المرحلة الجامعية وطلاب المرحلة الثانوية ،أستخدم الباحث مجموعة من الأدوات التى تتناسب والمنهج الوصفى التحليلى وقد توصلت الدراسة إلى النتائج الآتية: نوجد فروق دالة أحصائيا بين الثباب من الجنسين ومن الثانوى والجامعى فى الوجه القبلى والوجه البحرى لصالح الوجه القبلى على مقياس لواسل

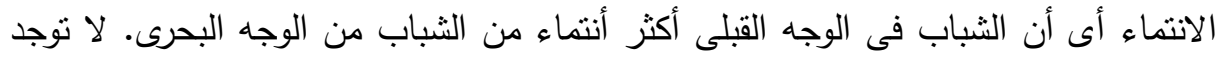

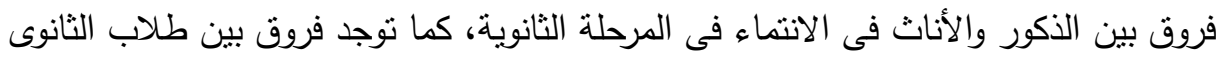

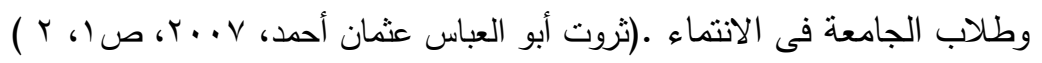




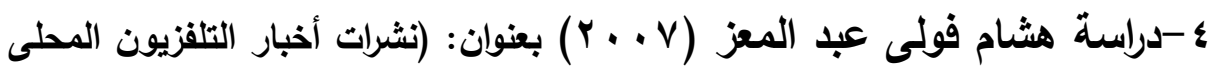
وعلاثتها بتدعيم الانتماء للمجتمع المطلى لاى المراهقين).

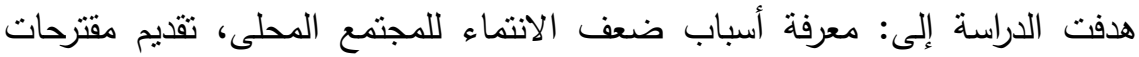

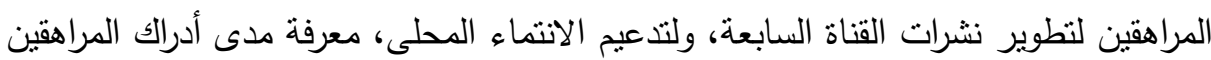

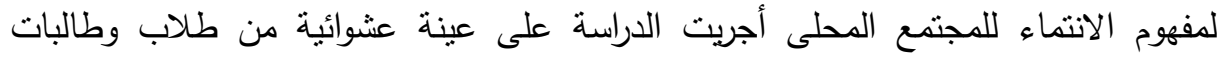

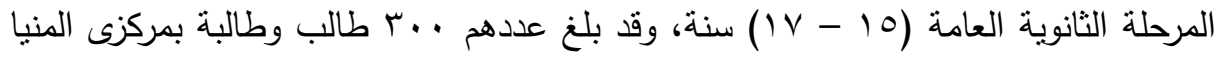
وأبو قرقاص، ومركز ملوى بمحافظة المنيا، تنتمى هذه الدراسة الى الدراسات الوصفية،

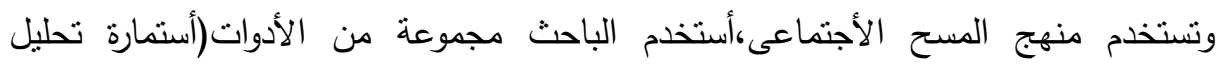
المضمون/ أستمارة أستيان ومقياس الانتماء للمجتمع المحلى).

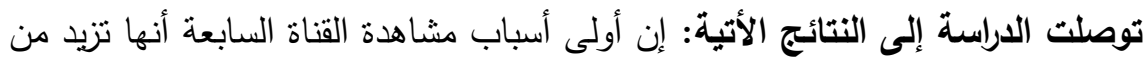

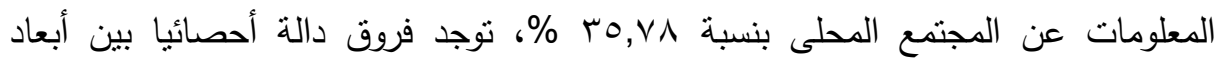

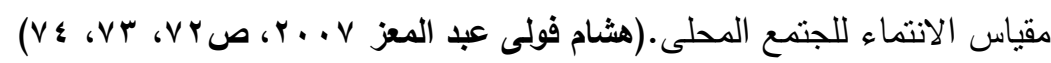

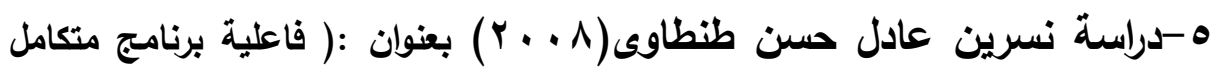
لتتمية الانتماء للوطن لاى أطفال المرحلة الأبتائية)

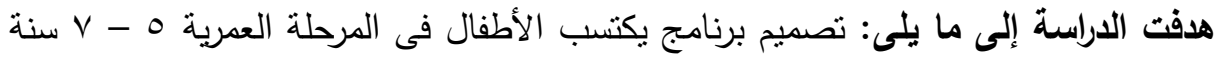

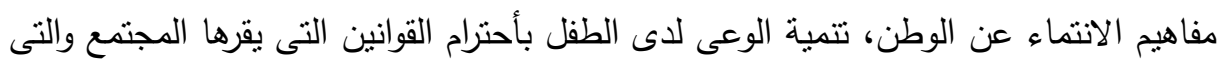

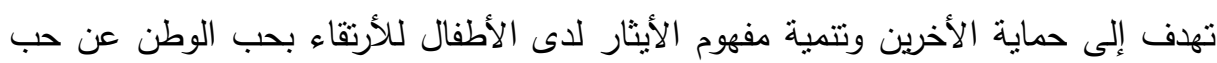

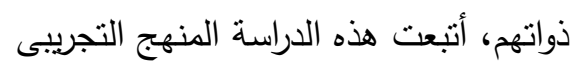

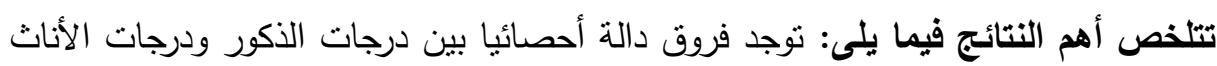

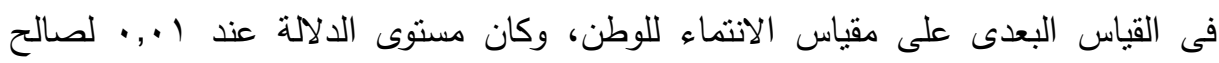

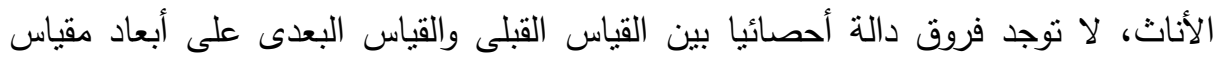

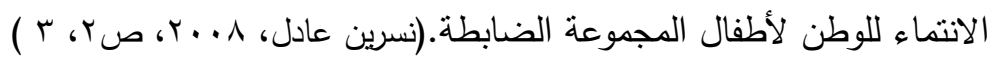


צ-دراسة رضا سعد فريا (9 ( . ب) بعنوان: (العلاقة بين الضغوط البيئية والانتماء

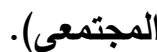

هدفت الدراسة إلى: التعرف على الضغوط البيئية المختلفة التى تؤثز على ترسيخ الانتماءتوضيح جدوى الانتماءعلى صعيدى الفرد والمجتمع ،وأستخدمت الدراسة المنهج الوصفى التحليلى،وتكونت عينة الدراسة من • ج فرد من احياء منشية ناصر ومصر الجديدة، واستخدم الباحث مجموعة من الأدوات تتتاسب ومنهج الدراسة (الملاحظة/أستمارة استبيان). وتوصلت الدراسة إلى عدد باتنتجة تم أعداد توصيات الدراسة على أساسها، وقد ركزت

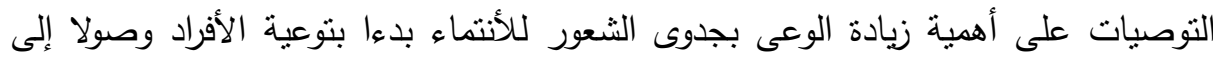
مستوى المؤسسات والقيادات والعمل هدفت الدراسة إلى: على أنخاذ السبل من أجل زيادة تماسك المجتمع.(رضا سع دفريد، 9 . . r) V-دراسة هبة الله سيد محمود (ع ا ـ Y) بعنوان: (الانتماء ومستوى الطموح لاى

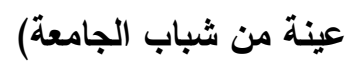

هدفت الاراسة إلى: الكثف عن الفروق فى مستوى الانتماء والطموح بين مجموعة من شباب

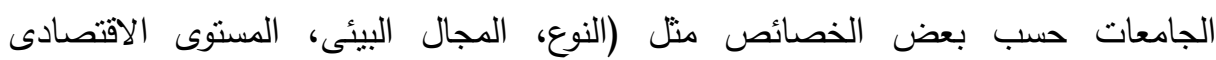
والاجتماعى والتعليمى)، واستخدمت الباحثة المنهج الوصفى المقارن وذلك لملائمته لموضوع الكئ

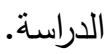

توصلت الدراسة إلى أنه توجد علاقة إرتباطية بين أجمالبمقياس الانتماء وإجمالى مقياس

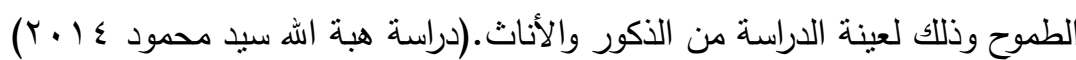

^-دراسة شيس ستيف( ( ץ): هدفت الدراسة إلى نطوير برنامج فى المدافعة البيئية لتدريب الناشطين والمدافعين عن البيئة فى مجال المصلحة العامة عينة الدراسة: مجموعة

منتقاة من القضايا البيئية.

وتوصلت الدراسة إلى النتائج التالية: التركيز على التعليم والتربية والمواطنة والتدريب النشط للنشاطين البيئيين فى المجتمع الدولى، وضع أستراتيجية لحل القضايا البيئية التى تدخل فى في

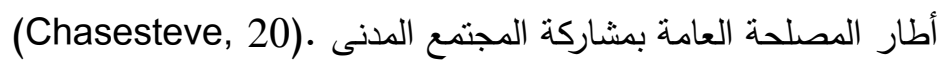




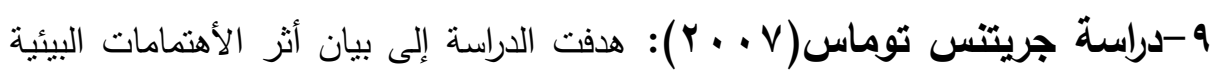
ووضعها فى أطار سياسى لجماعات الدمافعة.

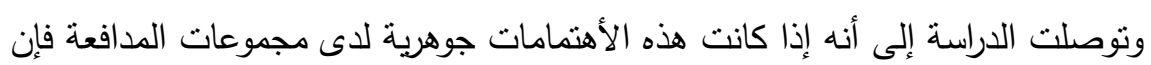

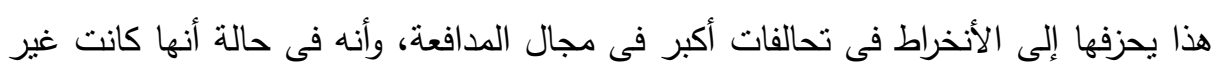

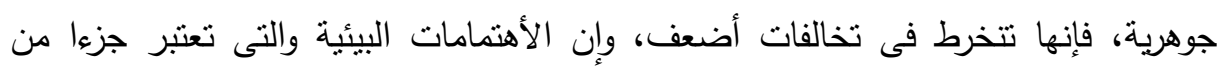

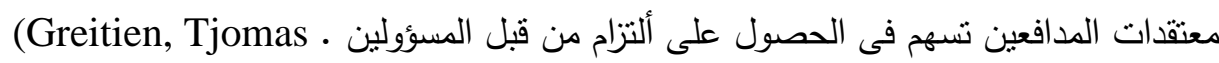
; 2007 , P. P: 87 - 90)

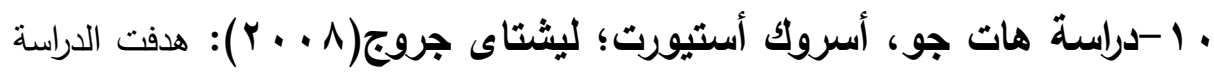

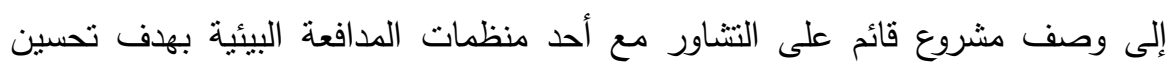

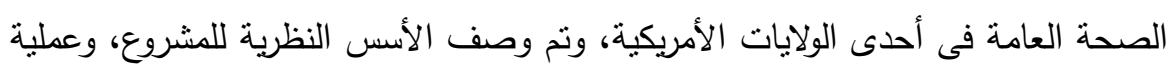

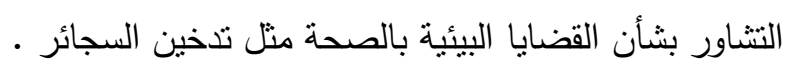

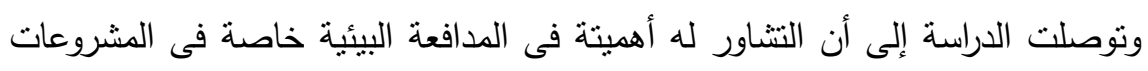
ذات العلاقة بالصحة العامة.

( Hart , Joy L: Esrock , stuart L: Leichty , Greg,2008 , P. 434)

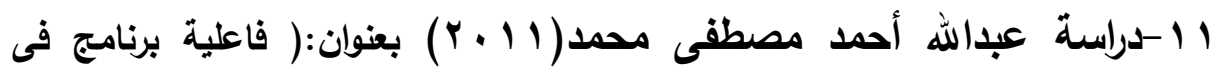

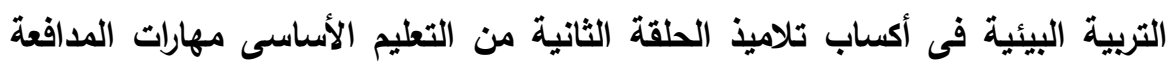
(البيئية).

هدفت الدراسة الى ما يلى: تحديد قائمة بمهارات المدافعة البيئية التى تتاسب تلاميذ الحلقة

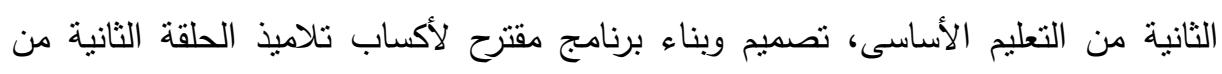

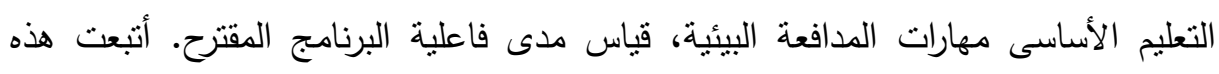

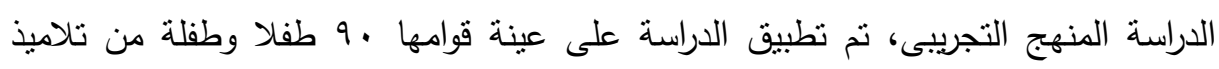

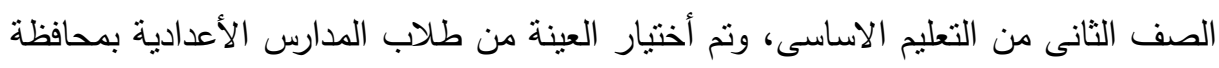

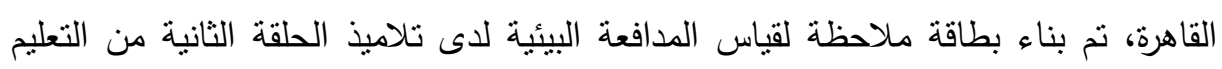

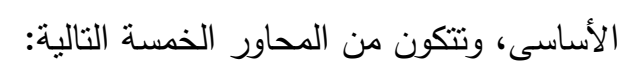
(مهارة الثشاور / مهارة الافناع / مهارة التفاوض/ مهارة الاتصال/ مهارة حل الشكلات).

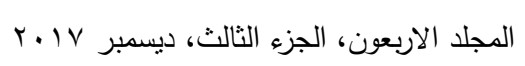




$$
\text { تتلخص أهم النتائج فيما يلى: }
$$

ا ـ توجد فروق ذات دلاله أحصائه عند مستوى الدلالة ه. ., · بين متوسطى درجات تلاميذ

المجموعة التجريبية بنين،وتلاميذ المجموعة الضابطة بنين،لمحاور بطاقة ملاحظة مهارات

المدافعة البيئية فى التطبيق البعدى لصالح المجموعة التجريبية.

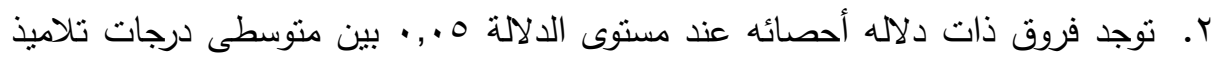
المجموعة التجريبية بنات،وتلاميذ المجموعة الضابطة بنات،لمحاور بطاقة ملاحظة دهنة مهارات المدافعة البيئية فى النطبيق البعدى لصالح المجموعة التجريبية.

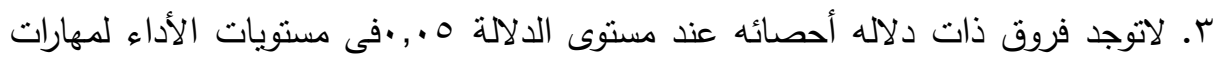

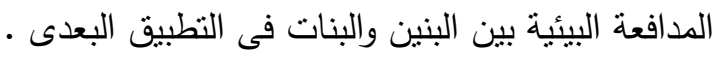

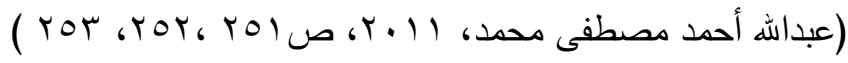
r ا -دراسة ولاء مصطفى خليل سيد النحاس( r ا ب r): بعنوان ( دور المتغيرات الأجتماعية والسلوكية فى تتمية مهارات المدافعة البيئية).

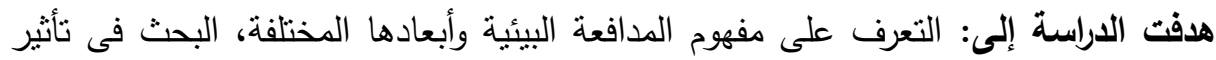
المتغيرات الأجتماعية والسلوكية فى نتمية مهارات المدافعة البيئية،من خلال الكثف عن درجة الأرتباط بين المتغيرات، أتبعت هذه الدراسة المنهج الوصفى التحليلى، نم تطبيق الدراسة على

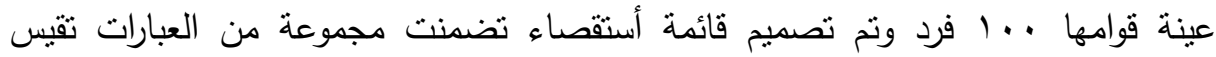
أتجاهات أفراد العينة تجاه متغيرات الدراسة . ل وتوصلت الدراسة إلى أنه: توجد علاقة أرتباط جوهرية ذات دلالة معنوية عند مستوى معنوية

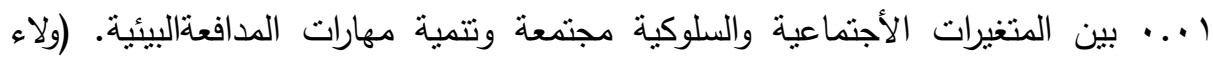

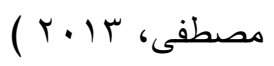




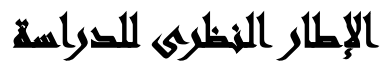

بعض النظريات التى تناولتها الدراسة:

1-نظرية أدلر فى الانتماء Adler: يرى أدلر أن الأنسان بعيش دائماداخل السياق

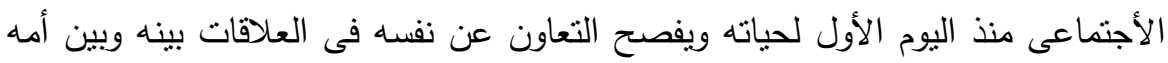

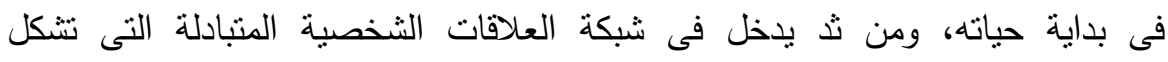

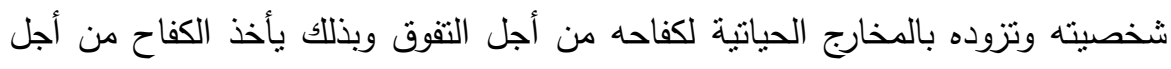

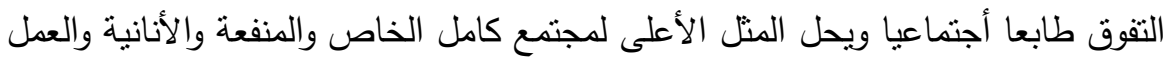

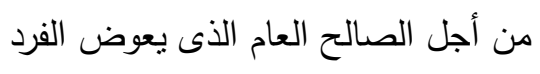

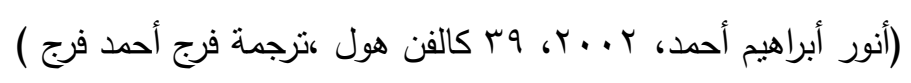

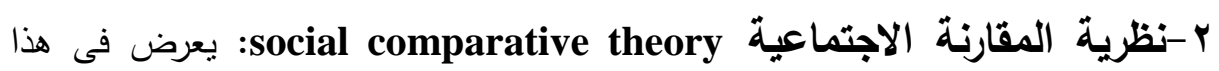

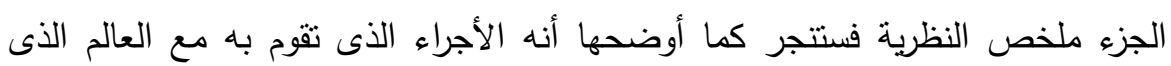

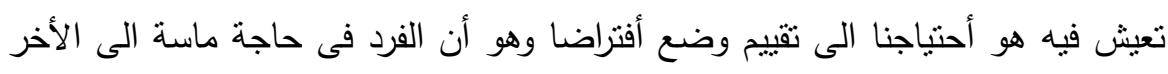

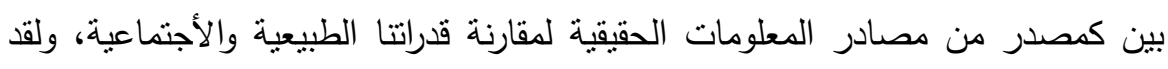

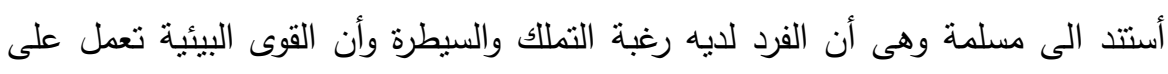

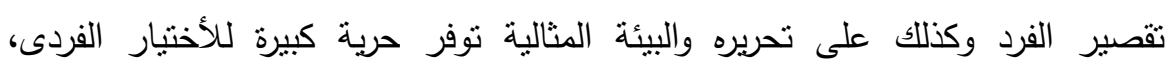

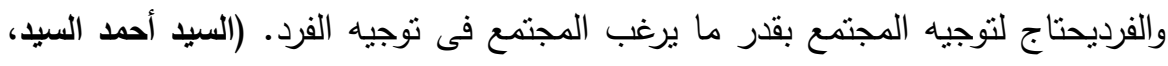

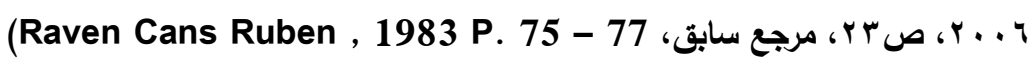
r-نظرية أريكسون Eriksson: وقدم اريكسون نظريته فى النمو النفسى الأجنماعى

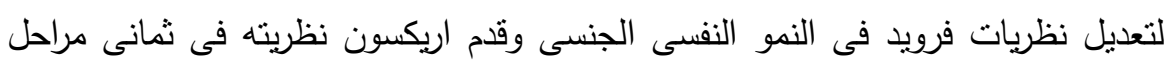

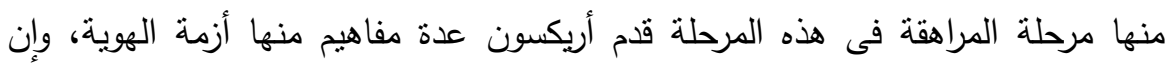

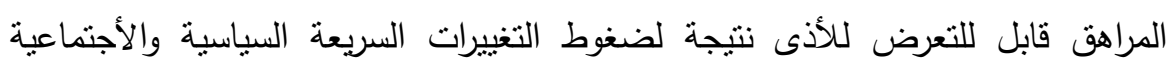

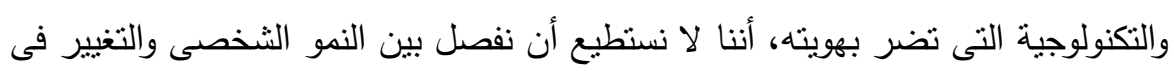

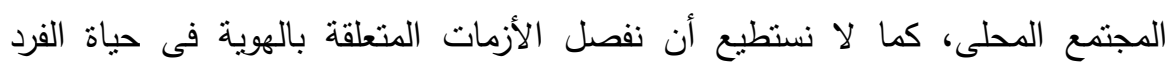


والأزمات المعاصرة فى التطور التاريخى .(ثروت أبو العباس عثمان، V... Y، ص ع ا، ترجمة

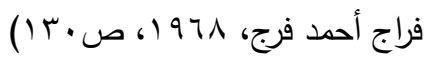

ع -نظرية النسق الايكولوجى: وهذه النظرية تتميز بالروئة الثاملة لتفاعل الإنسان مع البيئة المحيطة، حيث تهتم بدراسة التفاعلات بين الجوانب الفيزيقية والإنسانية معا، فيعتبر النسق الأيكولوجى مفهوما جديدا لتحليل علاقة الإنسان بالبيئة فيعد مفهوم النسق الأيكولوجى من المفاهيم البيولوجية التى استعارتها الأيكولوجيا البشرية عند نطوير إطارها التصورى المبكر ، ومؤداه أن كل المجتمعات الطبيعية للكائنات الحية التى تعيش وتتفاعل

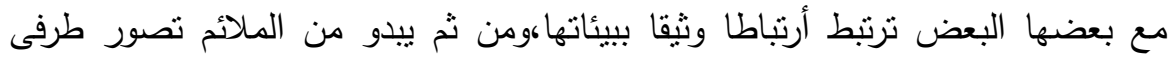

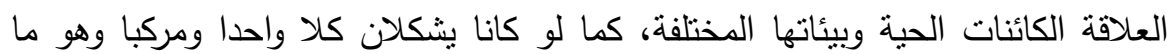

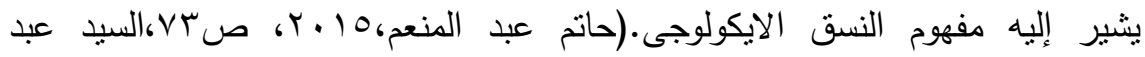

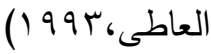

ه-نظرية Lewin فى العلاقة بين البيئة والسلوك الإنسانى: يعتبر lewin من أوائل علماء النفس الذين تبنوا المفاهيم والمبادىء الأيكولوجية فى دراسة سلوك الأنسان فقد

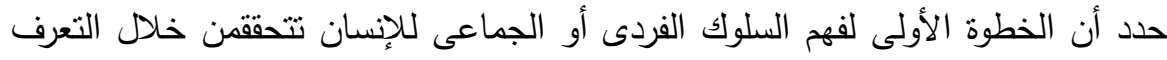
على الظروف والمواقف المحيطة به وقد عبر عن العلاقة بين سلوك الأنسان والبيئة المحبطة به من خلال المعادل B-F(P.E) والتى تتضمن مكوناتها ثناث عناصر

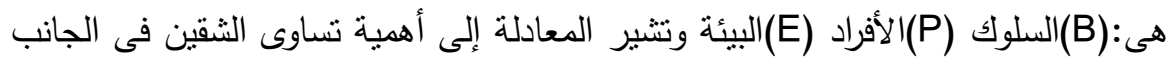
الأيمن وهما الأفراد والبيئة التى يتواجدون فيها حيث توضح المعادلة إلى أن التكامل بين

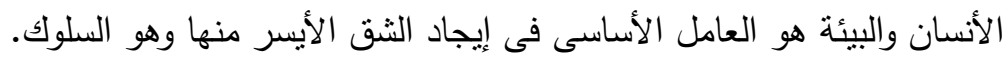
ومن هنا يتضح أن السلوك هو نتاج للتقاعل بين البيئة والأنسان وقد أكد LEWIN من النس خلال مفهومه المسمى بحيز الحياة (life space) على التفاعل المستمر بين القوى الداخلية للأنسان منل الأحتياجات الثخصية وبين الظروف الخارجية المتعلقة بكافة الظروف البيئية. (Lewin,k-Principles of topological Psychology,, 1936). 
צ-نظرية Barker للمجال السلوكى (Behavior Setting Theory): قام كلا من

(Barker 1968,Wicker 1979) بطوير بعض المفاهيم الخاصة بين السلوك والبيئة

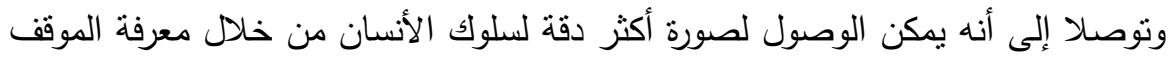
الذى يتواجد فيه وذلك أفضل من المعرفة بالسمات الفردية فقطهوقد أظهرت ننائج دراستهماأن سلوك كل إنسان يختلف على مدار اليوم بإختلاف المواقف التى يتعرض لها،كما أن التشابه بين المواقف والأحداث والظروف البيئية يحقق نشابها كبيرا فى سلوك لئك مجموعة مختلفة من الناس وبناء على ذلك فقد تم تأكيد أن الفرد بميل إلى ملائمة سلوكة الكية اللموقف الذى يتواجد فيههوكان من أهم تلك النظرية أهمية المحتوى (context) الذى يدور

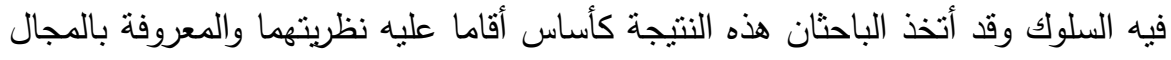
السلوكى(Behavior Setting Theory) والنى تتلخص فى الأتى:

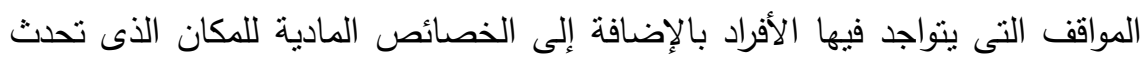

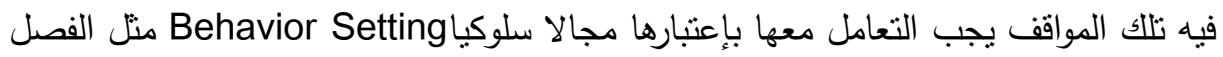

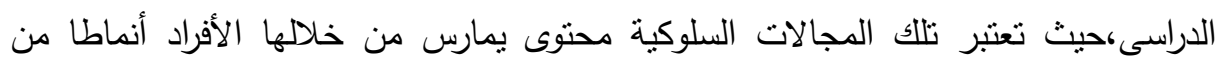
السلوك وردود الأفعال،ويكن أعتبار أى مكان يتواجد فيه الأفراد مجالا سلوكيا وبذلك فأن الكان

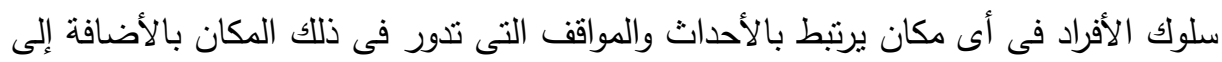

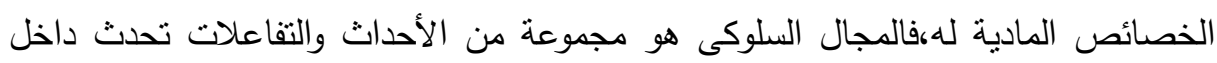
إطار مكانى وزمانى معروف ومحدد ويتكون الدجال السلوكى من الأفراد/الأدوات/العناصر

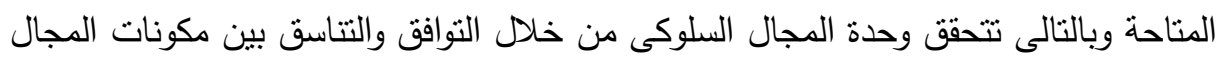
Barker,R.G „Ecological Psycology, 1968).(السلوكى من عناصر وأفراد وأدوات التهات 


\section{إلجراءايت التراسة (الإجراعاهت المنهبية)}

منهج الاراسة: استخدم الباحث فى هذه الدراسة المنهج الوصفى الارتباطى حيث أنه يتلائم وطبيعة الدراسة الحالية والتى تهدف إلى الكثف عن ما إذا كانت هناك علاقة بين الانتماء

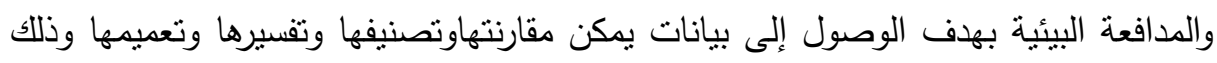

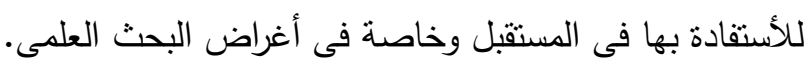

\section{مجالايت السراسمة}

تم تحديد حدودا زمنية ومكانية وبشرية لمجال الدراسة وهى كالأتى:

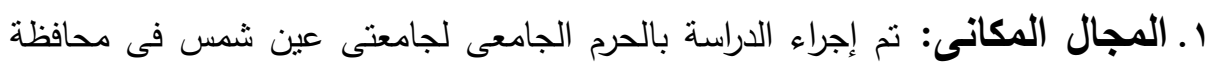
القاهرة (بيئه حضرية)، وجامعة بنها فى محافظة القليوبية (مدينة بنها) (بيئة أقل حضرية). حيث تم تطبيق المقاييس الخاصة بالدراسة على طلاب الجامعة من الذكور والأناث،

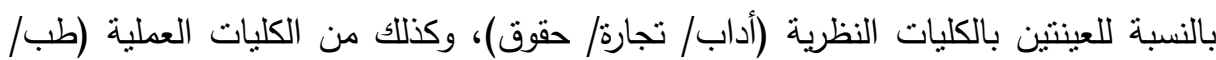
علوم/ هندسة). r. المجال الزمنى: استغرقت هذه الدراسة حوالى عامين ونصف تقريبا ومرت بالمراحل التالية:

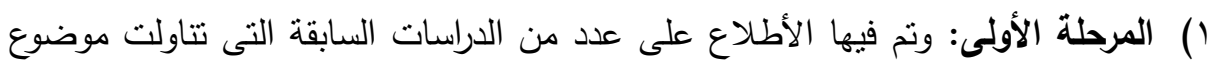
الدراسة ووضع الأطار النظرى الذى فسر ظاهرتى الانتماء والمدافعة البيئية والنظريات الموجهة للدراسة.

r) المرحلة الثانية: إعداد أدوات الدراسة وعرض المقاييس على المحكمين والخبراء وعمل تقنين للاختبارات (صدق، ثبات ) المقاييس. r) المرحلة الثالثة: الدراسة الأستطلاعية وتطبيق المقاييس على على عينة الدراسة وهى الفترة من

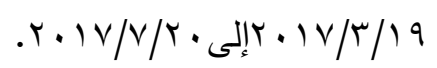
ع) المرحلة الرابعة: تقريغ البيانات وتحليل النتائج ووضع التوصيات. 
r. المجال البشرى: تتحدد عينة الدراسة فى عينة من طلاب الجامعات من الجنسين وييلغ

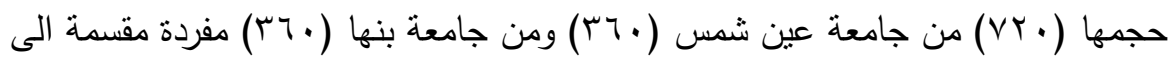

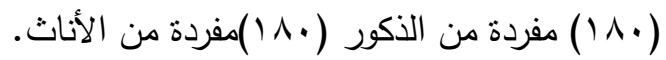

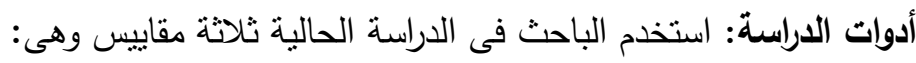
1-مقياس الانتماء للمجتمع المصرى - إعداد (هبة الله سيد)

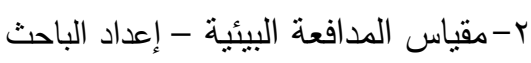

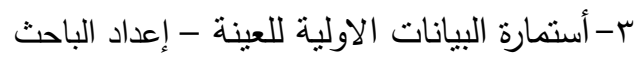

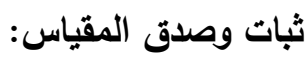
1-ثبات مقياس الانتماء على عينة من الطلاب: وصف المقياس: يتكون المقياس من (1) (عبارة،ويقوم المفحوص بإعطاء إجابة لكل عبارة

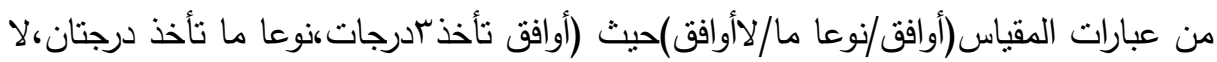
أوافق تأخذ درجة واحدة) فى العبارات الأيجابية والعكس فى حالة العبارات السلبية (أوافق تأخذ التذان درجة واحدة،وعا ما تأخذ درجتان، لا أوافق تأخذ سدرجات).ثم يتم جمع الدرجات فئ في درجة واحدة تعبر عن الدرجة الكلية للمقياس. تم التحقق من ثبات مقياس الانتماء من خلال الطرق التالية:

\section{أ-ثبات التنزئية النصفية Split-half method:}

- يوضح الجدول التالى العلاقة الأرتباطية بين العبارات الفردية والزوجية لمقياس الاتنماء .

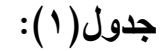

\begin{tabular}{|c|c|c|}
\hline أجمالي العبارات الفردي & أجمالي العبارات الزوجي & أجمالي مقياس الانتماء \\
\hline. .9 .7 & $. \wedge \leqslant V$ & معامل الأرتباط \\
\hline$\ldots .1 * *$ & $\ldots .1 * *$ & الدلالة الأحصائية \\
\hline $.94 \mathrm{~T}$ &. .911 & معامل التصحيح \\
\hline
\end{tabular}

قام الباحث بحساب مدى ثبات المقياس بطريقة التجزئة النصفية حيث تم تقسيم المقياس

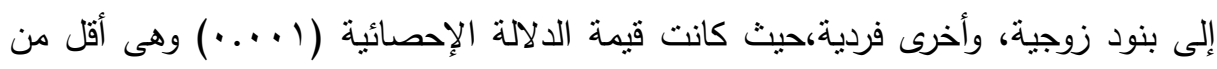
(147 (..) أى تتسم بالثبات بنسبة 99\%وكان معامل الارتباط بين العبارات الزوجية لرقياس 


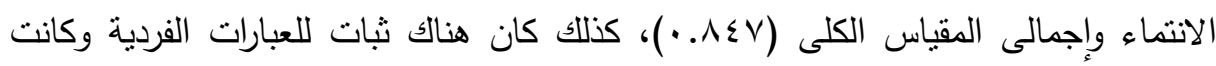
قيمة الدلالة الإحصائية (1) (....) ومعامل الارتباط بين العبارات الفردية لمقياس الانتماء

$$
\text { وإجمالى المقياس الكلى (7 • } 9 \text {. •). }
$$

ي-معامل ثبات ألفا كرونياخ Alpha

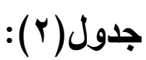

\begin{tabular}{|c|c|}
\hline مقياس الاتتماء & معامل الثبات \\
\hline \&1 & عدد العبارات \\
\hline. .170 & ألفا كرونباخ \\
\hline
\end{tabular}

يتضح من الجدول السابق أن قيمة ألفا (170. •) وهى قيمة تذيد عن (0. •) مما تؤكد

$$
\text { ثبات المقياس. }
$$

$$
\text { r-ثبات مقياس المدافعة البيئية على عينة من الطلاب: }
$$

وصف المقياس: يتكون المقياس من (• ع) عبارة، ويقوم المفحوص بإعطاء إجابة لكل عبارة

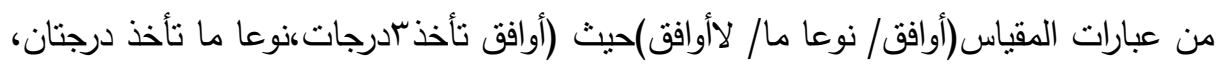

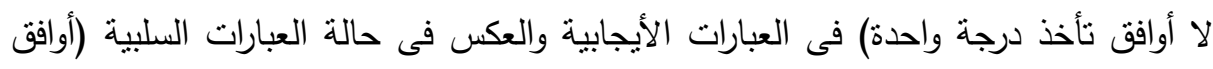

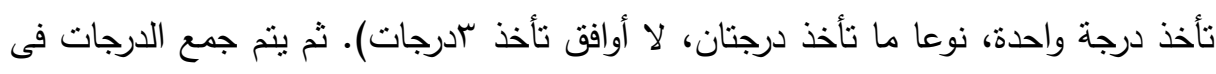
درجة واحدة تعبر عن الدرجة الكلية للمقياس. تم التحقق من ثبات مقياس المدافعة البيئية من خلائ الطرق التالية:

\section{أ ك-ثبات التجزئية النصفية:Split-half method}

ويوضح الجدول التالى العلاقة الأرتباطية بين العبارات الفردية والزوجية لمقياس المدافعة

\begin{tabular}{|c|c|c|}
\hline إجمالى العبارات الفردي & إجمالي العبارات الزوجي & إجمالى مقياس المدافعة البيئية \\
\hline. $.1 \mu q$ &. $.7 \mathrm{VO}$ & معامل الأرتباط \\
\hline$\ldots .1^{* * *}$ & ... 1 *** & الدلالة الأحصائية \\
\hline. . NTV &. .110 & معامل التصحيح \\
\hline
\end{tabular}

البيئية.

جدول(ب): 
قام الباحث بحساب مدى ثبات المقياس بطريقة التجزئة النصفية حيث نم تقسيم المقياس

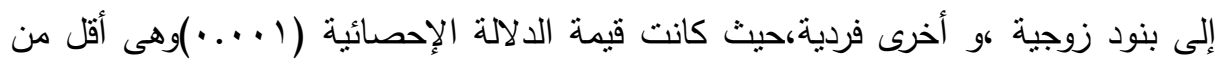
(1 (..)أى تتسم بالثبات بنسبة 99\%وكان معامل الأرنباط بين العبارات الزوجية لمقياس

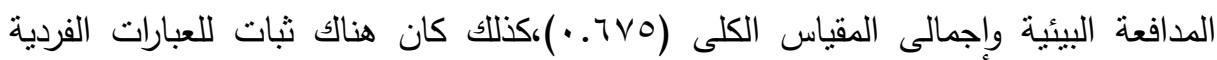

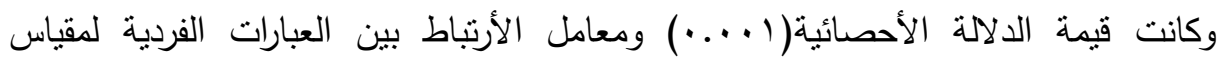

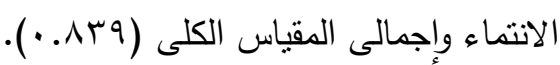

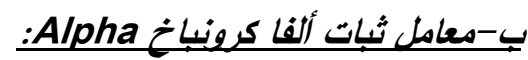
جدول(؟):

\begin{tabular}{|c|c|}
\hline مقياس المدافعة البيئية & معامل الثبات \\
\hline$\varepsilon$. & عدد العبارات \\
\hline$\therefore \vee 990$ & الفا كرونباخ \\
\hline
\end{tabular}

يتضح من الجدول السابق أن قيمة ألفا (90. •90)وهى قيمة تذيد عن (0. •) مما تؤكد

$$
\text { صدات المقياس. }
$$

1-أجرى الباحث حساب الصدق لأبعاد المقياس عن طريقأستخدام الباحث للصدق الظاهرى والذى يتضدن نسب أتفاق المحكمين على بنود المقياس وحذف العبارات التى نقل نسبتها

$$
\text { . \% . ع . }
$$

r-نم أسنطلاع آراء بعض المتخصصين والخبراء فى مجال مناهج البحث التأكدمن صدق المقياس،ثم تم تعديل بعض العبارات الطويلة،وحذف بعض العضى العبارات الغامضة. r-تم صياغة العبارات التى يمكن أن تعبرعن هدف المقياس ومفاهيم أبعاده.

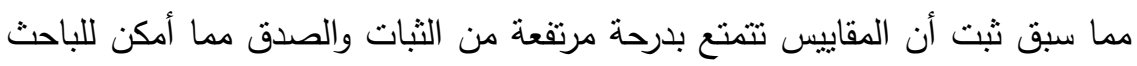
من أستخدامها فى الدراسة الراهنة. 


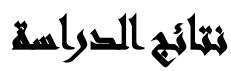

الفرض الأول: توجد علاقة دالة أحصائيا بين الانتماء والمدافعة البيئية لدى طلاب

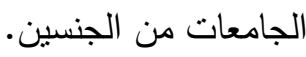
جدول(0):

\begin{tabular}{|c|c|c|}
\hline \multicolumn{2}{|c|}{ الانتماء } & \multirow{2}{*}{ معامل الأرتباط } \\
\hline الدلالة الأحصائية & $\mathrm{J}$ & \\
\hline$* * \ldots 1$ & .1007 & المدافعة البيئية \\
\hline
\end{tabular}

تشير نتائج الجدول السابق إلى وجود علاقة ارتباطية بين أجمالى مقياس الانتماء

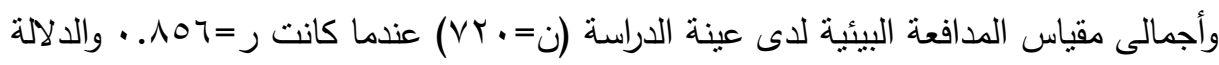

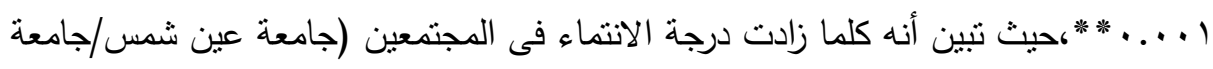
بنها) كلما ارتفع مستوى المدافعة البيئية لاى الطلاب من الجنسين.

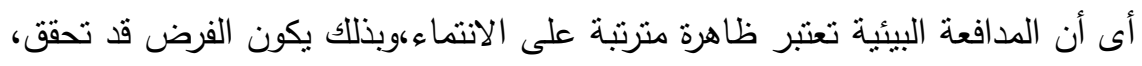
حيث وجد أن هناك علاقة أرتباطية بين درجات الطلاب على مقياس الانتماء،ودرجات أقرانهر

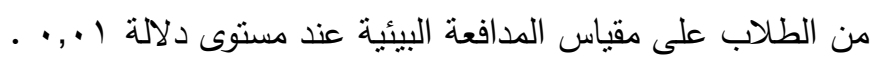
وبذلك نجد أن الانتماء لاى طلاب الجامعات يلعب دورا كبيرا فى نتكيل أنجاهتهم

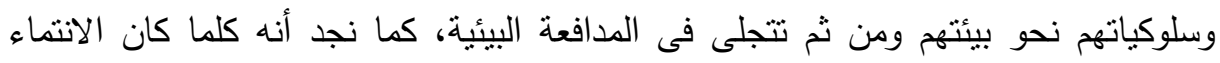
مرتفع يجعل الفرد أكثر دفاعا عن بيئتة التى يعيش فيها والعمل على تحسين بيئتة إلى لى لئه

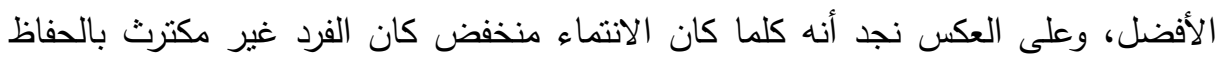
على بيئتة مما يعود علية بالسلبية واللامبالاة فى سلوكياتة تجاه الدفاع والحفاظ على البيئة. ونظرا لعدم وجود دراسات سابقة تتاولت علاقة الانتماء بالمدافعة البيئية،فيمن تفسير ذللك فى أطار نظرية فستتجر وأن حاجة الفرد للأنتماء للمجتمع الذى يعيش فيه وشعوره أنه جزءا لا يتجزء منه فتربطة بالقوى البيئية التى تعمل على تقصير الفرد وعلى تحريره، ومن هنا

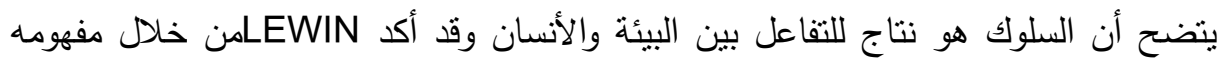


المسمى بحيز الحياة (life space) على التفاعل المستمر بين القوى الداخلية للأنسان منل الأحتياجات الثخصية وبين الظروف الخارجية المتعلقة بكافة الظروف البيئية. الفرض الثاني: نوجد فروق دالة أحصائيا فى الاتنماء بأختلاف الجامعات (جامعة حضرية) و (جامعة أقل حضرية).

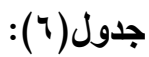

\begin{tabular}{|c|c|c|c|c|c|}
\hline \multicolumn{2}{|c|}{ اختبار ت } & \multicolumn{3}{|c|}{ مقياس الانتماء } & \multirow{2}{*}{ الجامعة } \\
\hline الدلالة الاحصائية & قيمة ت & الانحراف المعياري & الحستوسي & العدد & \\
\hline \multirow{2}{*}{$* * \ldots 1$} & \multirow{2}{*}{$1 Y .107$} & Q. TV & $V \leqslant .9 V$ & r. & عين شمس \\
\hline & & $9 . \wedge 1$ & AT.T0 & . רץ & بنها \\
\hline
\end{tabular}

من الجدول السابق نجد اختبار(ت) يوضح فروق ذات دلالة أحصائية بين متوسطي درجات طلبة جامعتي عين شمس وبنها علي مقياس الانتماء لعينة الدراسة حيث جاء متوسط

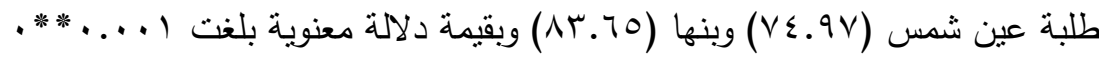
حيث يرجع الباحث هذةالنتيجة إلى أن أسلوب المعيشة فى بيئة أقل حضرية والتنشئة داخل الأسرة وكذلك الحياة المغلقة إلى حد ما عن الحياة بالبيئة المتحضرةفى القاهرة فهذا أنعكاس للواقع البيئى والمكانى فى نمط التتشئة،و ذلك يتفق مع نظرية أدلر فى الانتماء حيث أن الفرد يعيش دائما فى السياق الأجتماعى منذ ولادته وأن أنتماءات الفرد وأتجاهاته الفكرية

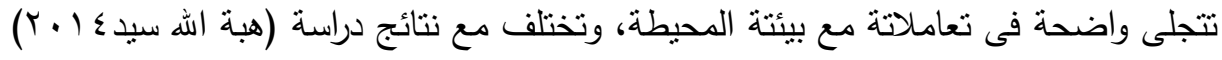
التى أثتبت وجود فروق داله أحصائيا بين درجات الثباب فى جامعة عين شمس وشباب جامعة بنها وذللك لصالح الثباب فى جامعة عين شمس. الفرض الثالث: توجد فروق دالة أحصائيا فى الانتماء بين الجنسين

\begin{tabular}{|c|c|c|c|c|c|}
\hline \multicolumn{2}{|c|}{ اختبار ت } & \multicolumn{3}{|c|}{ مقياس الانتماء } & \multirow[b]{2}{*}{ الجنس } \\
\hline الأحصائية & قيمة ت & الأنحراف & الحسابي & العدد & \\
\hline \multirow{2}{*}{$* * \ldots}$. & \multirow{2}{*}{$7.1 Y \leq$} & 0.11 & $\mathrm{~V} 7.0 \mathrm{r}$ & ry. & ذكور \\
\hline & & $0 . \leqslant 9$ & 11.11 & ry. & أناث \\
\hline
\end{tabular}

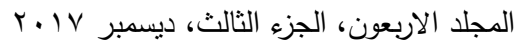


من الجدول السابق نجد وجود فروق ذات دلالة أحصائية بين منوسطي درجات الذكور والأناث علي مقياس الانتماء لعينة الدراسة حيث جاء منوسط الذكور (VT.Or) والأناث

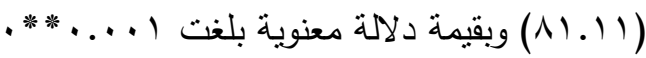
ويمكن تفسير وجود فروقذات دلاله أحصائية بين الذكور والأناث وذللك لصالح عينة

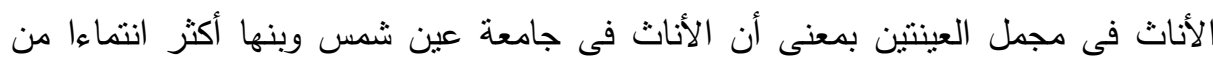

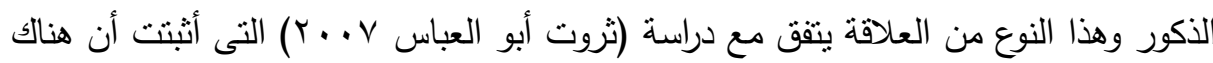

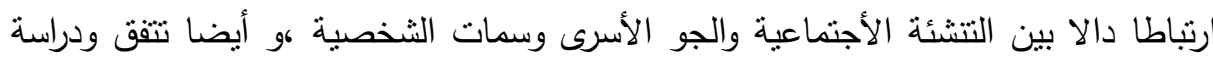

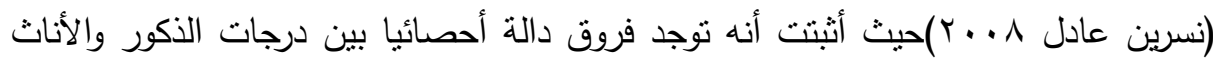

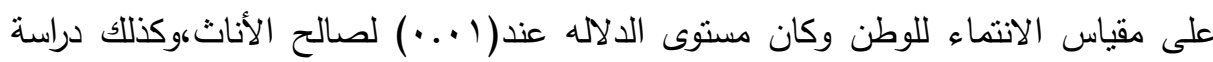
Janet,Ruth,1989()

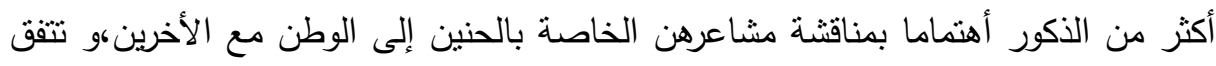
ودراسة (هبة الله سيد ؟ (ب)حيث أثنتت وجود فروق داله أحصائيا بين درجات الذكور

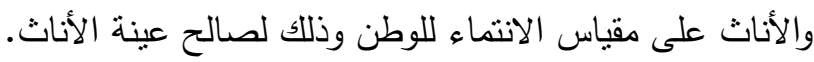
الفرض الرابع: نوجد فروق دالة أحصائيا فيالدافعة البيئيةبأختلاف الجامعات عين شمس /

جدول(^):

\begin{tabular}{|c|c|c|c|c|c|}
\hline \multicolumn{2}{|c|}{ اختبار ت } & \multicolumn{3}{|c|}{ مقياس المدافعة البيئية } & \multirow{2}{*}{ الجامعة } \\
\hline الالالة الأحصائية & قيمة ت & الأنحراف المعياري & الحستابي & 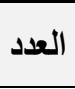 & \\
\hline \multirow{2}{*}{$* * \ldots 1$} & \multirow{2}{*}{11.774} & A.Ar & 17.91 & r.. & عين شمس \\
\hline & & $v .01$ & $91 . .4$ & ז. & بنها \\
\hline
\end{tabular}

من الجدول السابق نجد اختبار(ت) يوضح فروق ذات دلالة أحصائية بين متوسطي

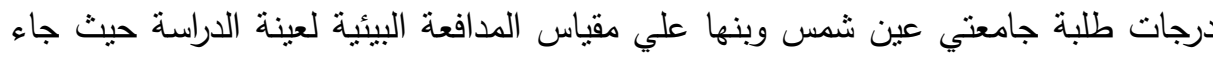

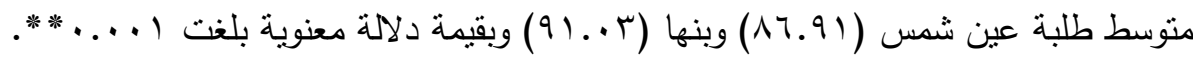


حيث نجد أن مستوى المدافعة البيئية يرتفع لدى طلاب جامعة بنها (بيئة أقل حضرية) عن طلاب جامعة عين شمس(بيئة حضرية). ويتفق ذلك مع نظرية النسق الأيكولوجى فى تفاعل الأنسان مع البيئة حيث تربط هذة

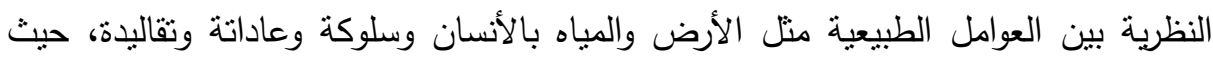

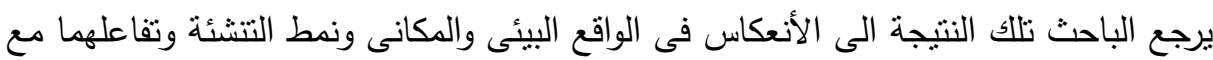
الفرد ونؤكد ذلك من خلال نظرية Barker للمجال السلوكى فالعلاقة بين السلوك الأنسانى والبيئة عندBarker تتحدد فى دراستهماأن سلوك كل إنسان يختلف على مدار اليوم بإختلاف

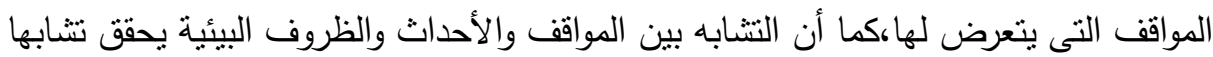
كبيرا فى سلوك مجموعة مختلفة من الناس وبناء على ذلك فقد نم تأكيد أن الفرد يميل إلى لى ملائمة سلوكة للموقف الذى يتواجد فيه، فالمواقف التى يتواجد فيها الأفراد بالإضافة إلى دئى دئى الخصائص المادية للمكان الذى تحدث فيه تللك المواقف يجب التعامل معها بإعنبارها مجالا سلوكياBehavior Setting منل الفصل الدراسى،حيث تعتبر تلك المجالات السلوكية محتوى يمارس من خلالها الأفراد أنماطا من السلوك وردود الأفعال،ويمكن أعتبار أى مكان يتواجد فئه

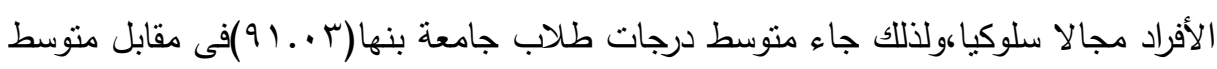

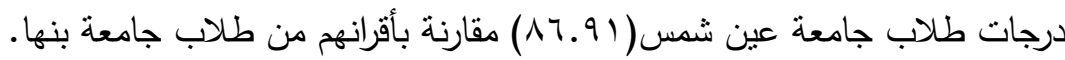
الفرض الخامس: توجد فروق دالة أحصائيا فى المدافعة البيئية بين الجنسين. جدول(9):

\begin{tabular}{|c|c|c|c|c|c|}
\hline \multicolumn{2}{|c|}{ اختبار ت } & \multicolumn{3}{|c|}{ مقياس المدافعة البيئية } & \multirow[b]{2}{*}{ الجنس } \\
\hline الدلالة الأحصائية & قيمة ت & الأنحراف المعياري & الحستابي & العدد & \\
\hline \multirow{2}{*}{$* * \ldots .1$} & \multirow{2}{*}{$\varepsilon .090$} & 1.19 & $19.0 \leqslant$ & r.. & ذكور \\
\hline & & V.q. & QY.EY & ז. & أناث \\
\hline
\end{tabular}

من الجدول السابق نجد اختبار (ت) يوضح وجود فروق ذات دلالة أحصائية بين

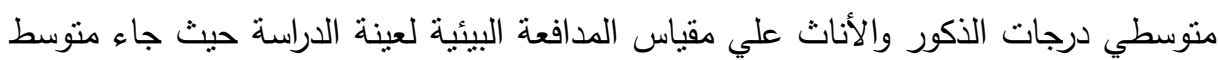

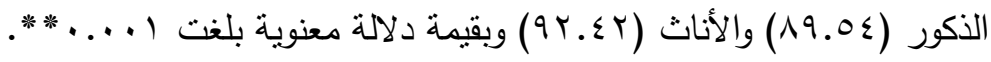


بمعنى أن الأناث فى جامعتى عين شمس وبنها أكثر مدافعة عن الذكور ، ويمكن تفسير

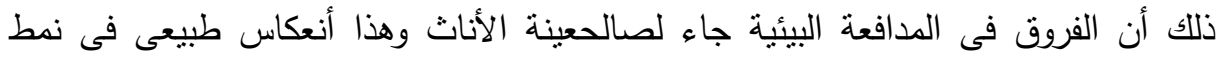
التنشئة الأجنماعية للأناث وفطرتهم من حيث تفضيل الأناث للفنون وتذوق المرأة للجمال

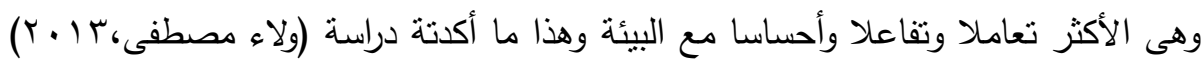

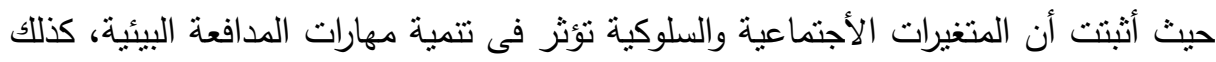
جاءت هذة النتيجة لتؤكد على ما فسرته نظرية أريكسون فى النمو النفسى الأجتماعبأننا لا لاعئه

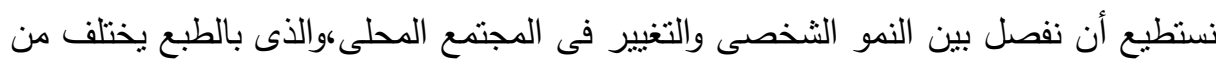
شخص لأخر ومن جنس لأخر، وقد أكد LEWIN على أن السلوك هو نتاج للتفاعل بين البيئة والأنسان،وذللك مايفسر أختلاف الذكور والأناث فيما بينهما وقد أثبتت النتائج الإجمالية لعينة الاراسة أنه: توجد علاقة دالة أحصائيا بين الانتماء

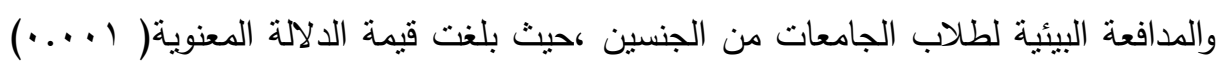

$$
\text { وهى قيمة دالة عند مستوى معنوية (0. . •). }
$$

\section{اللزوسيايت}

فى ضوء نتائج الاراسة ومناقشتها يوصى الباحث لإثراء الناحية البحثية بالأتى:

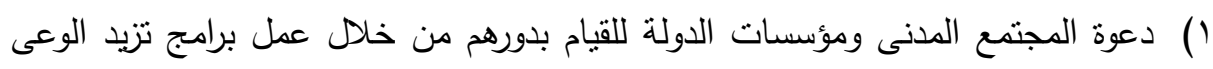
بجدوى الثعور بالانتماء والمدافعة البيئية.

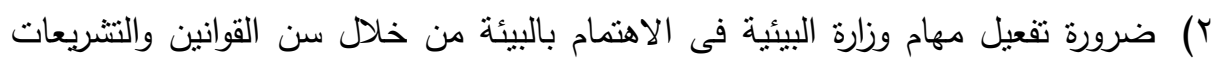
التى تمنع وتجرم التعدى على البيئة. r) تدعيم القيم البيئية الأيجابية فى مجتمعنا لغرس العادات الأيجابية للوصول لمستوى أفضل اجتماعيا ونفسيا وتربويا لأبنائنا.

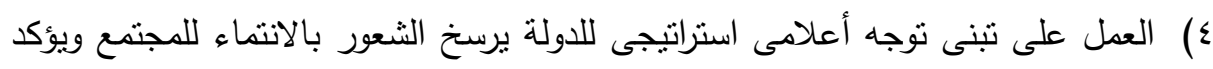

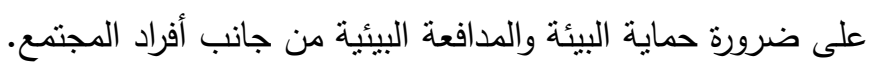


0) ضرورة تواصل الجامعات مع المجتمع المحلى وقياداتة من أجل تدعيم المدافعة البيئية فى الهي

$$
\text { المجتمع. }
$$

7) أنشاء موقع ألكترونى لكل جامعة تشير فيه لجهودها فى تعظيم الثعور بالانتماء للطلاب والمساهمة فى مجال الدفاع عن البيئة.

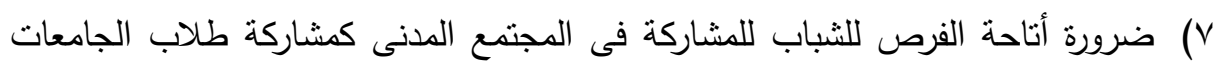
فى الأنشطة التطوعية لصالح الدفاع عن البيئة.

^) ضرورة عقد ندوات وحلقات عمل وبرامج تدريبية للتعريف بمفهوم وأهمية المدافعة البيئية. 9) ضرورة الأهتمام بالأحتياجات الأساسية من مسكن وخدمات صحية وتعليمية لأفراد

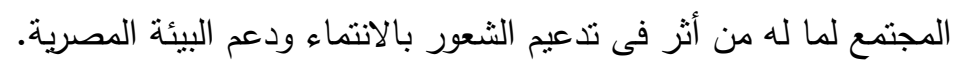

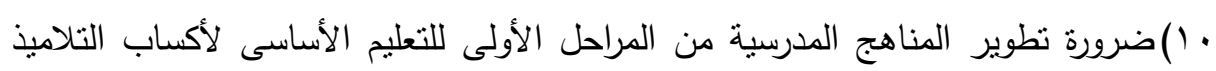
القيم الأيجابية كالأعتزاز بالانتماء والحفاظ على البيئة ونبذ المظاهر السلبية كالأنانية

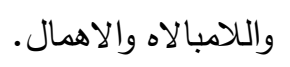

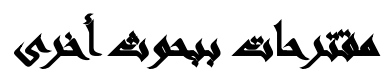

\section{يقترح إجراء الدراسات والبحوث التالية:}

ا. القيام بمزيد من الدراسات التى تتتاول علاقة المدافعة البيئية بمتغيرات نفسية واجتماعية

r. القيام بمزيد من الدراسات لألقاء الضوء على المدافعة البيئية وأهميتها وتطبيقاتها وبرامجها

$$
\text { واستراتيجيتها. }
$$

r. تصميم وبناء برامج تربوية تعمل على أكساب مهارات المدافعة البيئية لتلاميذ مراحل

$$
\text { التعليم المختلفة وبخاصة التعليم الأساسى. }
$$

ع. تصميم وبناء برامج تربوية تعمل على أكساب مهارات المدافعة البيئية لطلاب الجامعات. ه. إعداد دراسات تحليلية لمهارات المدافعة البيئية. 


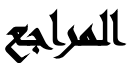

أبو الفضل جمال الدين بن منظور - لسان العرب، الجزء الساد، دار المعارف، القاهرة، 19V1

أحمد بن محمد بن على المقرى(9VV امج) المصباح المنير -دار المعارف-القاهرة

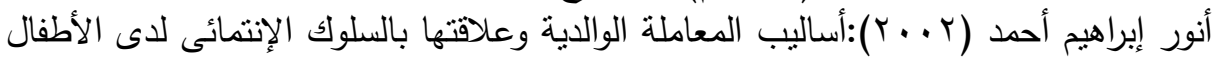

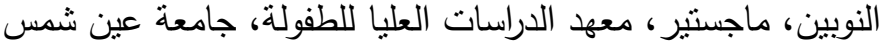

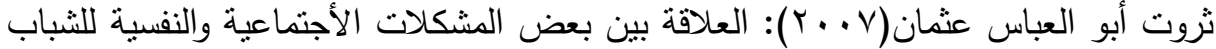

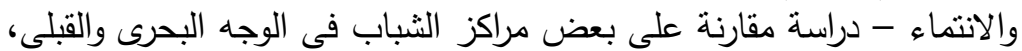

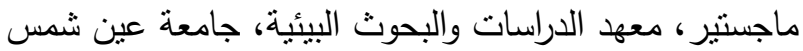

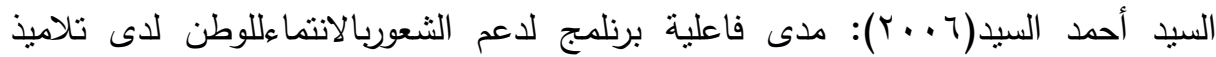

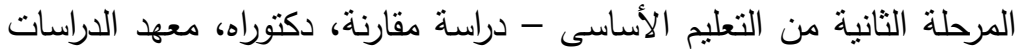

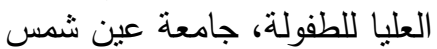

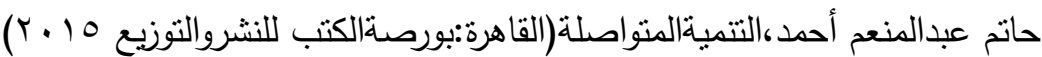

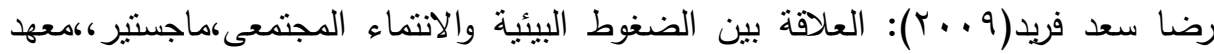

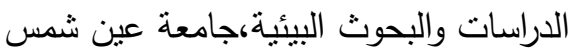

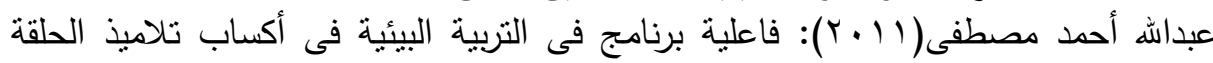

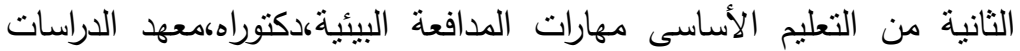
والبحوث البيئية،جامعة عين شمس البنانية

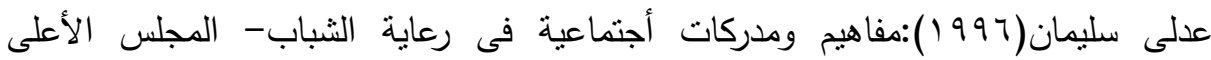
اللشباب-القاهرة

فهد إبراهيم الحبيب - الإتجاهات المعاصرة فى تربية المواطنة، مجلة المعرفة، العدد (07)

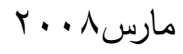

قدرى حفنى(r . . r): الطفل العربى والانتماء العربى، القاهرة، مطبعة الأمانة العامة لجامعة

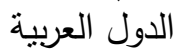

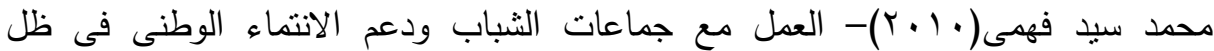

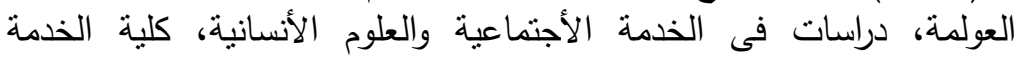

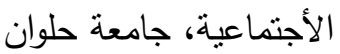

المعجم الوجيز - مجمع اللغة العربية، طبعة خاصنة بانية بالتربية والتعليم، 1991

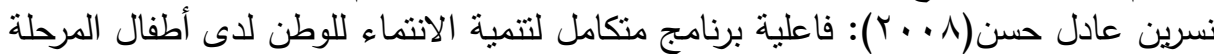

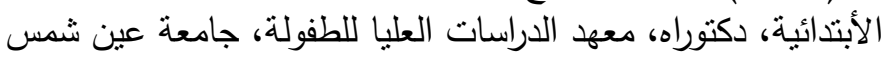


جمال شفيق أحمد وآخرون

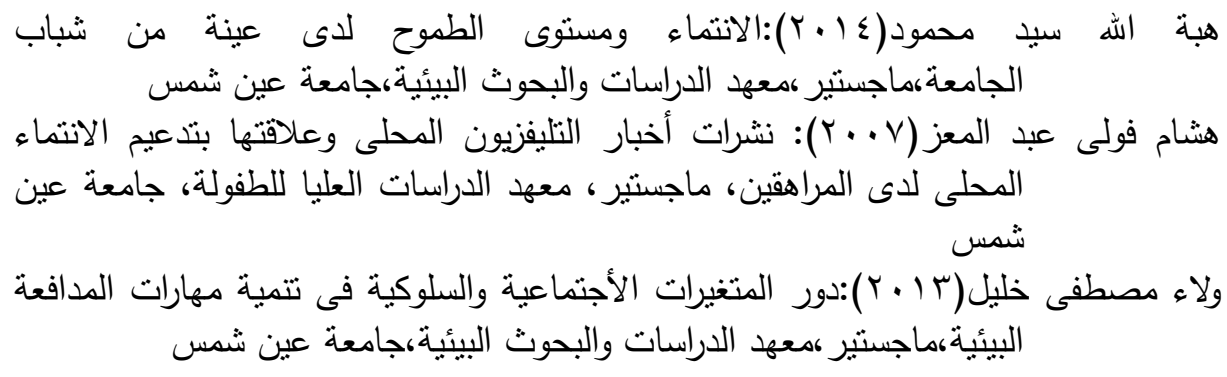

www.awu dam.org

www.alriyadh.com

www.startimer.com

Bhargavis.(2009).environmintal advocacy as acritical component of Enviromintal Education,paper suhmitted to Asian forum for cross- cultural dialogues, August 14th-20th.

Barker,R.G „Ecological Psycology:Concepts and methos For Studying the environment of human behavior-stanford,CA university press-1968.

Based on world net 3.0, Farlex clipart collection princetion university, Farex Inc. $2003-2008$.

Blair,N.(2012).inteegrating Advocacy and Environmental Education:A Response to Burns\&Norris paideusis, 20(1) 4-13.

Chase, steve, " Activist Training in the Academy" , Ph D. Dissertation inited states New Ha,pshire: Antioch New England Graduate school, 2006.

Collins essential english dictionary ibid .

Cohen, D., R. de la vega G. Watson. (2001) Advocacy for social justice Bloomfield, CT kumarian, press inc.

English H.B. \& English (1985): A.C.A. comprehensive Dictionary of psychological and psychoanalytical Terms, New York, Longmans, p. 64. 
Greitien, Tjomas J., " Bargaining of Beliefs: Agencies Advocacy Grops, And the Evoluation op pesticide Regulatorty Reform " , Ph D. Dissertation, united states 0162 lionis: Northen Lionis univerisyt; 2007 , P. P: $87-90$.

Hart, Joy L: Esrock , stuart L: Leichty , Greg, " Blowing smoke and Blawing Logic: Consulting on Gigarette Excise tax increases Message" , journal articles: Reports Fescriptivedescriptive communication eductio, Vol 57 No. 4, oct. 2008 , P. 434 .

Janet, Ruth (1989): Differences in Need for Affiliation and the qualities of intimacy and nurturance with in preadolescent friend ships, Diss. Abstract international, vol. 44, No. 011, May, p. 5044-B.

Lewin,k -Principles of topological Psychology,„New York-McgrawHill 1936.

Law encyclopedia. West'd enyclopedia of american Law, by the Gale Group 1998.

Merriam - Wester's dictionary of law „Merriam - Webster, Inc., 1996.

Solmonson,L.(2010)Developing advocacy skills :Aprogram model.Retrieved from:http:counslingoutfitters.com/vistas10/article27pdf

Priscilla weeks: Culture \& Agriculture , Anthriopology and Environmental Adocacy, Fall 1999, vol. 21 , No. 3 , 2004 ., PP. 1-2.

The american heritage dictionary of the english language, lpid .

The American Heritage, Dicrionary of the English Language, Fourth Edition Published by Houghton Mifflin Company, 2009. 
جمال شفيق أحمد وآخرون

Torney - Purta, Judith, Lehman, R. Os Wald, H. and Schulz. W. (2002): Citizen ship and education in twenty eight countries: Civil knowledge and engagement at age Fourteen. IEA. http: //wam.umd.edu/iea/. Loisto <Bruno.www.OnlineJournal.DE/2003-21.index.html Dictionart.com, LLC. From Legal Dicrtionary, 2009.

\title{
AFFILIATION AND ITS RELATIONSHIP TO ENVIRONMENTAL ADVOCACY FOR UNIVERSTY STUDENTS OF BOTH SEXES - A FIELD STUDY
}

Ahmed, G. Sh. ${ }^{(1)}$; Abdel Monem, A. M. ${ }^{(2)}$ and Fathy, A. M. 1) Institute of Postgraduate Childhood Studies, Ain Shams University

2) Unit ofSocial Studies and Social Surveys, League of Arab States

\begin{abstract}
This study belongs to the pattern of analytical descriptive studies,which aims to describe and analyze psychological aspects related to environmental affiliation and advocacy in a sample of university students of both sexes, which is the comparison between students of an urban university (Ain-Shams ) university and another university is less civilized (Banha) university . Therefore, this study is considered descriptive studies that measure the relationship between two variables, independent variable is (the belonging) and the dependent variable is (the environmental advocate)

This study was based on a sample social survey method for students from Ain-Shams university males and females, and a sample of students from Banha university males and females.
\end{abstract}

The study attempts to test the validity of the following assumptions:

There is a statistically significant relationship between environmental affiliation and advocacy among university students of both sexes, there are statistically significant differences in affiliation 
among universities ,(urban university) and (less urbanized university ), there are statistically significant differences in gender affiliation, there are statistically significant differences in environmental advocacy among universities and statistically significant differences in environmental advocacy between the sexes .

The sample of the study was a random sample of students of both sexes. The sample was (720) from Ain-Shams university (360) from Banha university (180) single male (180) single female.

Data were also processed using tests to detect individual differences between averages, standard deviation and Pearson correlation coefficient.

The study found that there is a positive correlation between environmental affiliation and motivation in the study sample of males and females.

The recommendation of the study: call on civil society and state institutions to do their part through the implementation of programs that increase awareness of belonging and importance of environmental advocacy, and the need to active the function of the ministry of environment through enactment of laws and legislation that prevent and criminalize the infringement on the environment. 